\section{Pacific Northwest}

National Laboratory

Operated by Battelle for the

U.S. Department of Energy

\title{
Flammable Gas Release Estimates for Modified Sluicing Retrieval of Waste from Selected Hanford Single-Shell Tanks
}

\author{
J. L. Huckaby \\ B. E. Wells
}

March 2004

\author{
Prepared for the U.S. Department of Energy \\ under Contract DE-AC06-76RL01830
}




\title{
DISCLAIMER
}

This report was prepared as an account of work sponsored by an agency of the United States Government. Neither the United States Government nor any agency thereof, nor Battelle Memorial Institute, nor any of their employees, makes any warranty, express or implied, or assumes any legal liability or responsibility for the accuracy, completeness, or usefulness of any information, apparatus, product, or process disclosed, or represents that its use would not infringe privately owned rights. Reference herein to any specific commercial product, process, or service by trade name, trademark, manufacturer, or otherwise does not necessarily constitute or imply its endorsement, recommendation, or favoring by the United States Government or any agency thereof, or Battelle Memorial Institute. The views and opinions of authors expressed herein do not necessarily state or reflect those of the United States Government or any agency thereof.

\author{
PACIFIC NORTHWEST NATIONAL LABORATORY \\ operated by \\ BATTELLE \\ for the \\ UNITED STATES DEPARTMENT OF ENERGY \\ under Contract DE-ACO6-76RLO183O
}

Printed in the United States of America

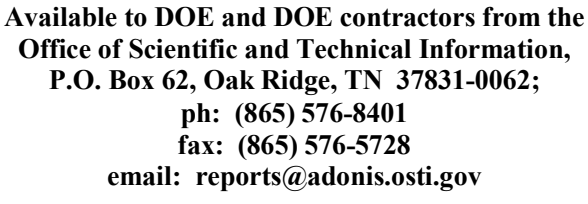

Available to the public from the National Technical Information Service, U.S. Department of Commerce, 5285 Port Royal Rd., Springfield, VA 22161

ph: (800) 553-6847

fax: $(703) 605-6900$

email: orders@ntis.fedworld.gov

online ordering: http://www.ntis.gov/ordering.htm 


\title{
Flammable Gas Release Estimates for Modified Sluicing Retrieval of Waste from Selected Hanford Single-Shell Tanks
}

\author{
J. L. Huckaby \\ B. E. Wells
}

March 2004

Prepared for

the U.S. Department of Energy

under Contract DE-AC06-76RL01830

Pacific Northwest National Laboratory

Richland, Washington 


\section{Executive Summary}

The high-level radioactive wastes in many single-shell tanks (SSTs) at the Hanford Site are to be retrieved by a modified sluicing method that uses water jets to dissolve the water-soluble waste and mobilize the water-insoluble waste. Retrieval operations will liberate any waste gases trapped in the wetted solid waste matrix, and these gases will be released into the tank headspaces. Because the trapped gases include the flammable species hydrogen, methane, and ammonia, a concern exists that a flammable mixture could be formed in the tank headspaces. This report combines conservative retained gas inventory estimates and tank data with anticipated waste retrieval rates to estimate the potential headspace flammability of selected SSTs during modified sluicing waste retrieval operations. Considered here are nine of the 12 tanks from the 241-S tank farm (241-S-107, 241-S-111, and 241-S 112 are not considered) and Tank 241-U-107.

This report is intended to support the specification of process controls that ensure flammable conditions do not develop in the tank headspaces. Consequently, the physical scenarios considered, the models developed to estimate retained gas releases and the tank headspace compositions under these scenarios, and the model input data are intended to conservatively assess the potential to reach headspace flammability. The analyses are intended to address worst-case conditions and establish reasonable upper bounds on the achievable flammability of the tank headspaces. Flammable retained gas inventories, for example, are based on the 95th percentile developed by Barker and Hedengren (2003), giving 95\% confidence that actual inventories are smaller than those used in the calculations.

Gas releases and headspace flammability were evaluated for three general scenarios: a very aggressive dissolution and erosion of saltcake waste by water jets impinging on the waste surface, the drainage of interstitial liquids from saltcake during a shutdown of the retrieval process, and the dissolution of saltcake by unsaturated liquids during a shutdown of the retrieval process.

The simple model of waste retrieval using the modified sluicing approach indicated that the flammable gas headspace concentrations can rapidly approach the action level of $25 \%$ of the lower flammability limit (LFL) when the tank is passively ventilated. While it is not necessary to use the portable exhauster to maintain the headspace hydrogen concentration below this action level, retrieval rates would probably be limited by the slow removal of flammable gases by passive ventilation. It was determined that using a portable exhauster anywhere in the assumed operating range of 270 to $475 \mathrm{cfm}$ would prevent the headspaces from reaching the $25 \%$ of LFL action level even if the water jets are very effective at eroding the saltcake. Specific guidelines are developed to ensure that, in the event of a catastrophic loss of the retrieval pump and portable exhauster, headspace flammability will not reach the LFL. 
This report is Revision 1 of PNNL-14271. This revision expands the analysis of interstitial liquid drainage-induced gas releases to address a general retrieval scenario (the previous version of this report assumed a center-out retrieval approach and conditions). Tank waste conditions (waste volumes, interstitial liquid levels, temperatures, retained gas void fractions, etc.) have also been updated from the previous version. 


\section{Acknowledgments}

The authors would like to thank Steve Barker for providing key retained gas inventory and composition data, Lenna Mahoney and Chuck Stewart for conducting a peer review, and Blaine Barton, Mike Grigsby, Larry Kripps, and Ryan Smith for helpful comments on early drafts of this report. Thanks are also due to Sheila Bennett and Dave Payson, our technical editors. 


\section{Contents}

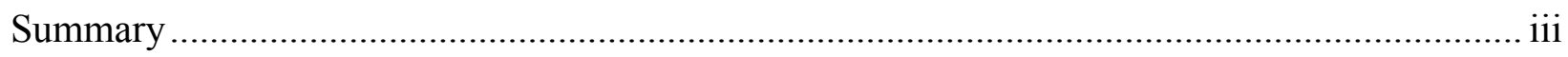

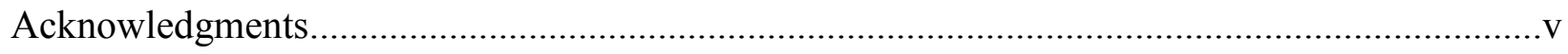

Acronyms and Abbreviations ……………………......................................................... ix

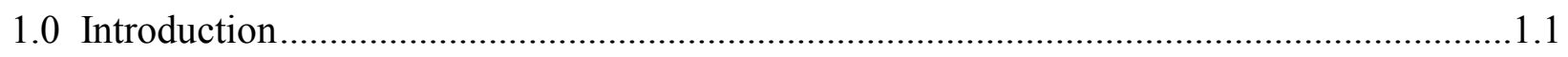

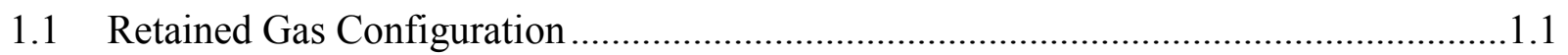

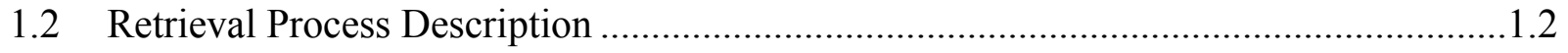

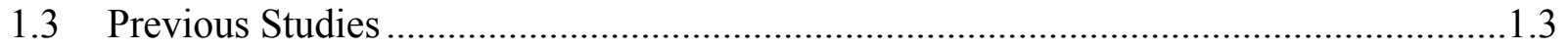

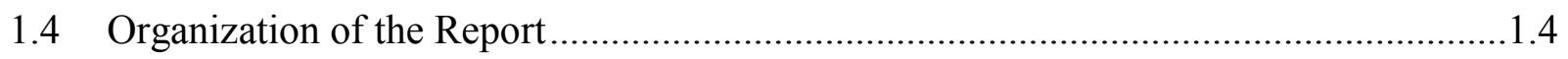

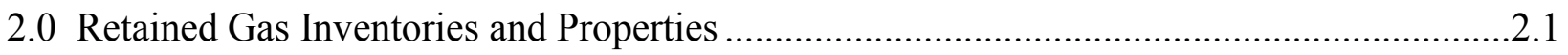

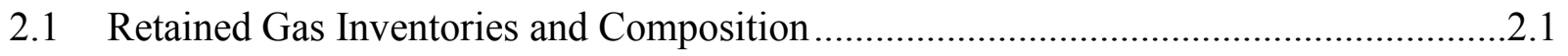

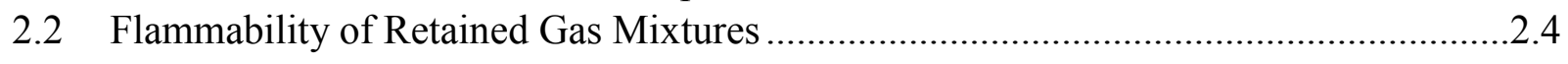

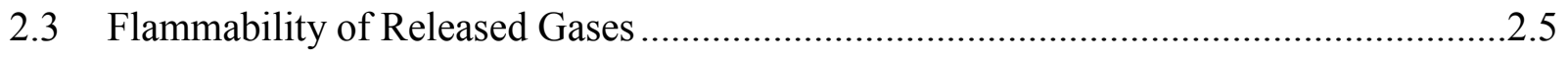

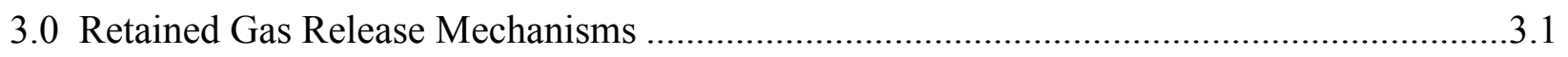

3.1 Supernatant and Interstitial Liquid Removal ...............................................................

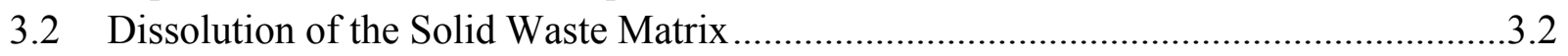

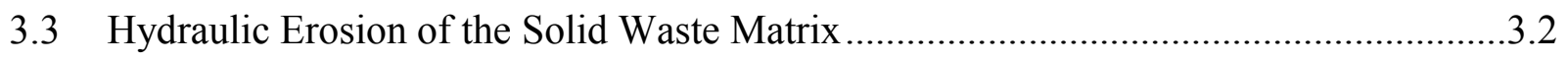

4.0 Models for Gas Release Rates and Headspace Flammability................................................. 4.1

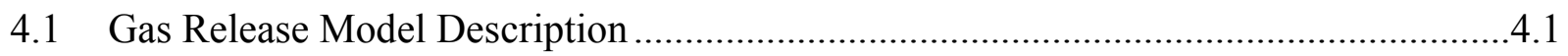

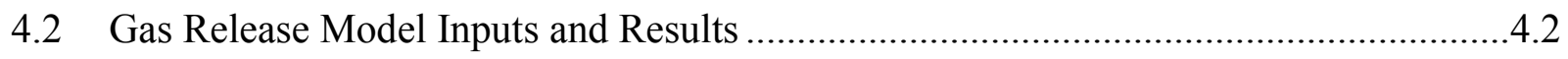

4.3 Model Extended for Ventilation of Headspaces ............................................................4.4

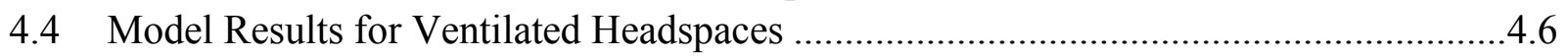

4.5 Gas Releases During Process Shutdowns …………................................................... 4.8

4.5.1 Liquid Drainage after Process Shutdown .............................................................

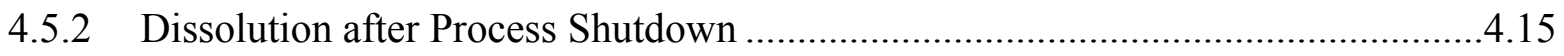

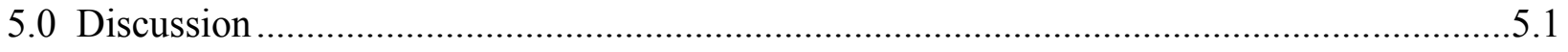

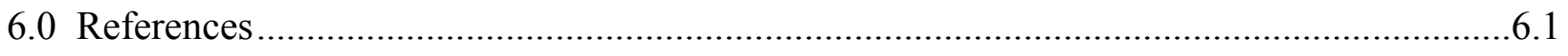

Appendix A: Monte Carlo Simulation Results ...........................................................................

Appendix B: Gas Release Rate Model Equations................................................................... B.1

Appendix C: Headspace Gas Concentration Model ................................................................... .

Appendix D: Expression for Minimum Interstitial Liquid Level to Prevent Significant Drainage-Induced Gas Releases ............................................................................. 


\section{Figures}

1.1 Illustration of the Center-Out Waste Retrieval Strategy ..................................................

4.1 Tank S-102 Headspace Flammability as a Function of Time for Various Ventilation Rates.

4.2 Headspace Flammability as a Function of Time for Several Tanks Given a Ventilation Rate of $450 \mathrm{cfm}$

4.3 Change in Tank Headspace Flammability Due to Drainage of Interstitial

Liquid as a Function of Effective Central Pool Radius

4.4 Change in Tank S-102 Headspace Flammability Due to Drainage of Interstitial Liquid as a Function of Central Pool Effective Radius for Selected Initial Central Pool Liquid Heights

4.5 Change in Tank S-102 Headspace Flammability Due to Drainage of Interstitial Liquid as a Function of Volume Fraction of Waste Retrieved for Selected Initial Central Pool Liquid Heights

4.6 Change in Tank S-102 Headspace Flammability Due to Drainage of Interstitial Liquid as a Function of Volume Fraction of Waste Retrieved when Waste above the Initial Interstitial Liquid Level Is Retrieved and Not Retrieved

4.7 Minimum Pump Well Liquid Level, $h_{P W L^{*}}$, as a Function of Volume Fraction of Waste Retrieved

\section{Tables}

2.1 Retained Gas Distribution Data

2.2 Input Parameter Values and Calculated Retained Gas Inventories ...................................2.4

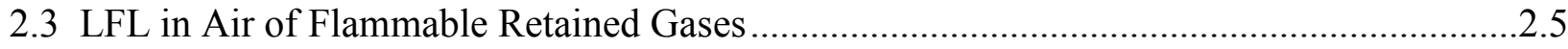

2.4 LFL in Air of Retained Gas Mixtures by Tank.................................................................2.5

2.5 Calculated Headspace Flammability by Tank if All Retained Gas Were Released into the Tank Headspace Instantaneously ..................................................2.6

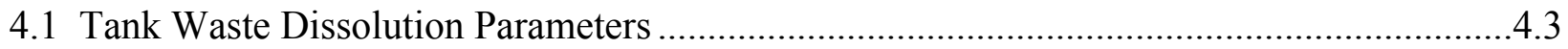

4.2 Maximum Gas Release Rates by Tank for 80 gpm Water Application Rate ......................4.4

4.3 Parameters for Calculation of hPWL* ......................................................................4.14

4.4 Water Volumes Potentially Resulting in a 75\% of LFL Increase in Tank Headspace ........4.16 


\section{Acronyms and Abbreviations}

$\begin{array}{ll}\text { atm } & \text { atmosphere } \\ \text { gal } & \text { gallon } \\ \text { gpm } & \text { gallons per minute } \\ \text { kgal } & \text { thousands of gallons } \\ \text { LFL } & \text { lower flammability limit (in air) } \\ \text { scfm } & \text { standard cubic feet per minute } \\ \text { SpG } & \text { specific gravity } \\ \text { SST } & \text { single-shell tank } \\ \text { TCD } & \text { Tank Characterization Database } \\ \text { vol\% } & \text { volume percent } \\ \text { wt } \% & \text { weight percent }\end{array}$

\section{Symbols}

$\alpha \quad$ Retained gas void fraction

$\beta_{L C} \quad$ Volume of brine created by dissolution per volume of water added

$\beta_{B W} \quad$ Volume of bulk waste dissolved per volume of water

$\chi_{H} \quad$ Volume fraction of hydrogen in the retained gas

$\Gamma \quad$ Ratio of waste volumes above and below the interstitial liquid level

$\lambda \quad$ Fraction of retained gas that is flammable

$\phi \quad$ Porosity

$\rho_{B R} \quad$ Saturated brine density

$\rho_{I L} \quad$ Interstitial liquid density

$\rho_{S} \quad$ Solids density

$\rho_{W} \quad$ Water density

$\mathrm{C}_{\mathrm{CH} 4} \quad$ Fraction of $\mathrm{CH}_{4}$ in flammable portion

$C_{H 2} \quad$ Fraction of $\mathrm{H}_{2}$ in flammable portion

$C_{i} \quad$ Volume fraction (i.e., concentration)

$C_{N H 3} \quad$ Fraction of $\mathrm{NH}_{3}$ in flammable portion

$C_{H}\left(t_{1}\right) \quad$ Concentration of the gas at time $t_{1}$

$F \quad$ Specified mass fraction of undissolved solids in the product stream

$h_{I L} \quad$ Initial height of interstitial liquid

$h_{P O O L 0} \quad$ Initial height of liquid in the central pool

$L F L_{M I X} \quad$ Lower flammability limit in air of the mixture

$L F L_{i} \quad$ Lower flammability limit of the $i^{\text {th }}$ species in air

$M_{D S} \quad$ Mass of dissolved solids per volume of water applied

$M_{I L} \quad$ Mass of interstitial liquid per bulk waste volume 


$\begin{array}{ll}M_{S} & \text { Mass of solids per bulk waste volume } \\ P_{H S} & \text { Tank headspace pressure } \\ P_{W} & \text { Average hydrostatic pressure on retained gas } \\ P_{W^{*}} & \text { Average hydrostatic pressure on retained gas after drainage of interstitial liquid } \\ Q_{B O U T} & \text { Volumetric flow of waste out via the retrieval pump } \\ Q_{F G} & \text { Volumetric flammable gas release rate } \\ Q_{H 2 O} & \text { Volumetric water application rate } \\ Q_{R G} & \text { Volumetric retained gas release rate } \\ Q_{V O U T} & \text { Volumetric flow of air out via ventilation system } \\ Q_{W I N} & \text { Volumetric flow of water into the tank } \\ R & \text { Radius of the tank } \\ r & \text { Effective radius of central pit } \\ T_{H S} & \text { Temperature of the headspace } \\ T_{W} & \text { Temperature of the retained gas } \\ T_{W^{*}} & \text { Temperature of the retained gas after drainage of interstitial liquid } \\ V_{B} & \text { Volume of bulk waste disturbed per volume of water applied } \\ V_{G} & \text { Volume of retained gas at in situ (waste) pressure and temperature } \\ V_{G 75 \%} & \text { Volume of retained gas at in situ (waste) pressure and temperature required to raise } \\ & \text { the headspace flammability by 75\% of the LFL } \\ V_{G H S} & \text { Volume of retained gas at atmospheric pressure and headspace temperature } \\ V_{H 2 O} & \text { Volume of water available for saltcake dissolution in tank } \\ V_{H S} & \text { Volume of tank headspace } \\ V_{H S^{*}} & \text { Volume of tank headspace after drainage of interstitial liquid } \\ V_{H S O} & \text { Volume of tank headspace at time zero } \\ V_{I L} & \text { Volume of interstitial liquid } \\ V_{S} & \text { Volume of dry void-free solids in the tank } \\ V_{T} & \text { Volume of waste } \\ V_{T A N K} & \text { Volume of (empty) tank } \\ V_{W<I L L} & \text { Volume of waste below the interstitial liquid level } \\ & \end{array}$




\subsection{Introduction}

The high-level radioactive wastes in many single-shell tanks (SSTs) at the Hanford Site are to be retrieved by a modified sluicing method. This modified sluicing method will direct jets of water at the waste surface to erode and mobilize the waste. Waste that is readily soluble in water will be dissolved; waste that has a very low solubility will be hydraulically mobilized and sluiced to the inlet of the retrieval pump.

Waste gases residing in the solid waste matrix will be released into the tank headspace as the waste is retrieved. These retained waste gases include the flammable species hydrogen, methane, and ammonia, and there is a concern that these gases could produce a flammable mixture in the tank headspaces during retrieval operations. This report combines conservative retained gas inventory estimates and tank data with anticipated waste retrieval rates to estimate the potential headspace flammability of selected SSTs. The SSTs considered here are 9 of the 12 tanks in the 241-S tank farm (Tanks 241-S-107, 241-S-111, and 241-S-112 are excluded) and Tank 241-U-107 (U-107). ${ }^{\text {(a) }}$

\subsection{Retained Gas Configuration}

The wastes in the 10 SSTs of interest are composed primarily of water-soluble salts with various lesser amounts of metal oxides and other water-insoluble species. The solid wastes were generally laid down in layers via settling and precipitation as batches of slurry waste were added and the supernatant liquids removed. Gradual salt crystal growth caused by cooling of the waste and Ostwald ripening has resulted in the formation of saltcake, a granular solid with varying structural strength (Hedengren et al. 2001). Though most of the tanks of interest have had their drainable liquid wastes removed, much liquid remains as trapped droplets held by surface tension in the interstices of the drained saltcake, and much liquid remains below the level at which drainage due to gravity is effective.

Chemical and radiolytic processes in the aqueous waste generate gases (e.g., hydrogen and nitrogen) that form small bubbles within the solid matrix. These may grow within the confines of the matrix but do not generally deform the solid matrix itself. ${ }^{(\mathrm{b})}$ When small, the bubbles are effectively separated from other bubbles and the headspace by interstitial liquid and are relatively immobile. Gradual bubble growth results in larger bubbles that migrate upward through the matrix and eventually are released into the tank headspace. In dry waste regions above the interstitial liquid level, the interstices of the solid matrix are sufficiently interconnected to allow waste gases to diffuse upward to the headspace (Peurrung et al. 1996; Huckaby et al.

(a) Hanford tanks are designated by the prefix 241-followed by the tank farm label and tank number. In this report, as in common usage, the prefix is omitted.

(b) Particle-displacing bubbles can be formed under certain conditions, as described by Stewart et al. (1996), but are not significant in the tanks of interest in this report. 
1999). Thus, gases that have migrated to the top of the interstitial liquid diffuse relatively quickly through the dry waste to the headspace, and the interstices of the drained waste above the interstitial liquid level can be considered part of the tank headspace.

\subsection{Retrieval Process Description}

The retrieval of waste from the tanks of interest will involve dissolution, erosion, and sluicing to mobilize and transfer the waste solids to the suction of a retrieval pump. While some changes to the retrieval strategy and methods can be expected, the general approach is expected to follow three stages:

- In the first stage, water will be added to the well created during the installation of the retrieval pump and allowed to soak and dissolve the saltcake surrounding the pump. The resulting brine will be pumped out to a DST. Several fill, soak, and pump cycles will be necessary to enlarge the well to a size that supports continuous application of water. This first stage will involve relatively small quantities of water (less than 10,000 gal at any one time), and the retrieval of waste (and the release of gases) will be relatively slow.

- During the second stage, three remotely operated nozzles in the tank headspace will direct jets of water at the waste surface to erode and dissolve the saltcake. Water supply limitations result in a nominal water application rate of about $80 \mathrm{gpm}$ and an estimated maximum application rate of about $100 \mathrm{gpm}$. The brine and any suspended solids produced by this method will drain to the pump and be pumped out at a nominal rate of $80 \mathrm{gpm}$. This is depicted in Figure 1.1. While the preferred retrieval strategy is to direct the water jets at the sloping walls surrounding the central pool and retrieve the waste by a center-out method, water may also be distributed over the upper waste surface to effect a top-down retrieval. The second stage will begin as soon as the central pit is large enough to support a continuous process and last until the central pit extends roughly to the tank wall.

- The third and last stage will consist of sluicing the remaining waste, much of which will have already released its gas, toward the pump inlet. Only minor gas releases are expected during this last retrieval period. These stages and other aspects of the retrieval strategy are described in Process Control Plan for Saltcake Dissolution Retrieval Demonstration in Tank 241-S-112 (Cowin et al. 2003). 


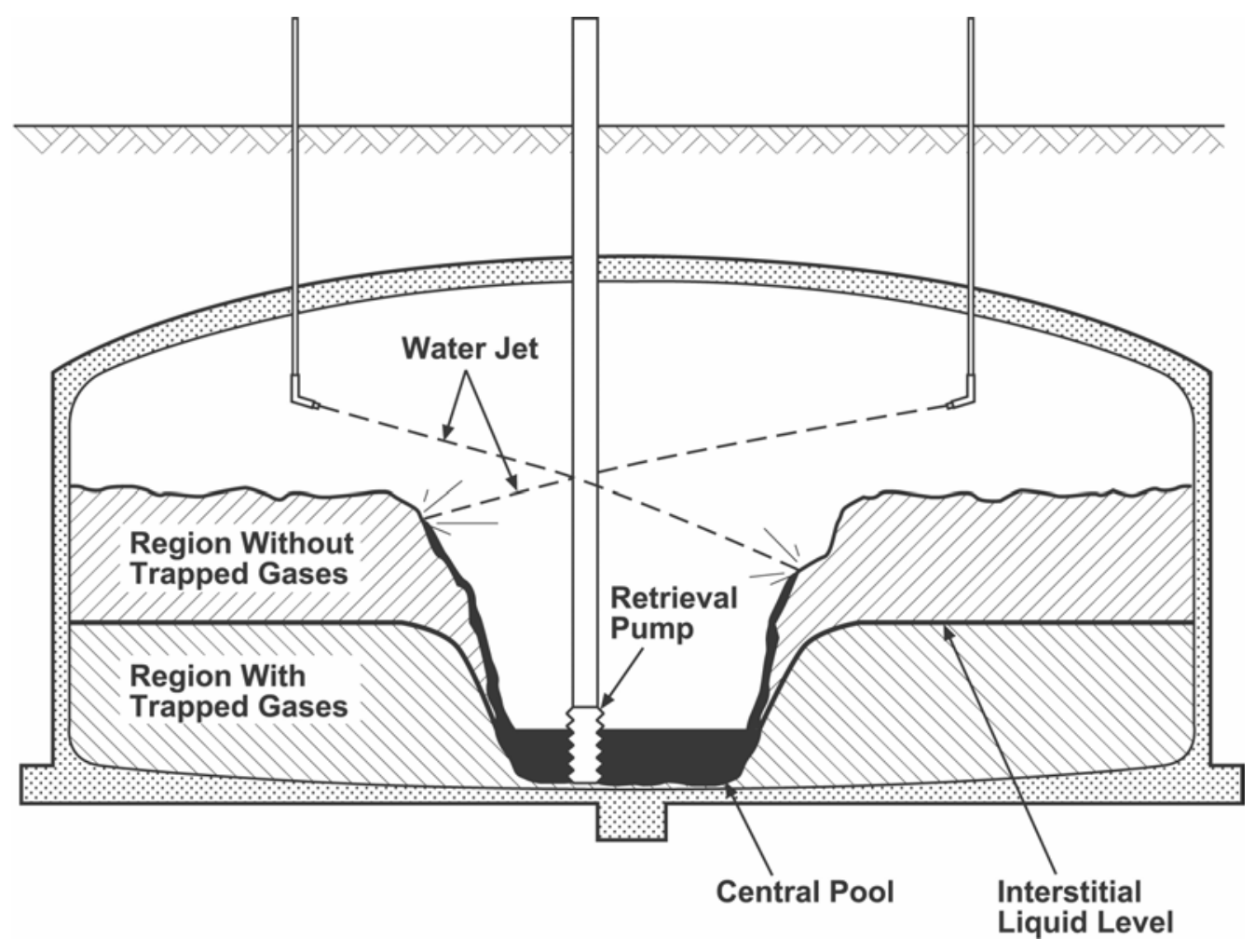

Figure 1.1. Illustration of the Center-Out Waste Retrieval Strategy

Figure 1.1 also illustrates that, when a center-out retrieval strategy is being applied, erosion and dissolution of waste over any extended period of time (i.e., hours) will include waste that is above the interstitial liquid level (in the tanks where such waste exists). Water applied to erode and dissolve the upper, gas-free portion of the waste will cause very little gas release. Similarly, gas releases will not be increased if chunks of the upper, gas-free portion of the waste slough or break off and tumble into the central pool.

\subsection{Previous Studies}

In past work, gas release rates during retrieval of saltcake SSTs by water dissolution were evaluated for typical interim stabilization brine-pumping rates of 5-10 gpm (Stewart 2001). The generic tank represented in that study was assumed to have waste properties and gas content similar to Tank U-107. Stewart (2001) argued that gas release rates would be limited by the waste dissolution rate, which, for operational reasons, was approximately equal to the brinepumping rate. With a 10 -gpm pumping rate, a retained gas volume fraction of 0.2 , and estimated passive ventilation of $2.5 \mathrm{scfm}$, the headspace hydrogen concentration was predicted to exceed the action limit of $6,250 \mathrm{ppm}$ in about three days, but the headspace was predicted to remain below the lower flammability limit (LFL) of $4 \mathrm{vol} \%$ hydrogen to the end of the planned U-107 dissolution tests, about six weeks later. 
Later work specific to retrieval of Tank S-112 considered brine pumping rates from 1 to 1,000 gpm with tank headspace ventilation rates from 1 to $1,000 \mathrm{scfm} .{ }^{(a)}$ In that study, the headspace hydrogen concentration was predicted to remain well below the LFL at the highest pumping rates even without active ventilation because the retained gas inventory in S-112 was estimated to be relatively low. A ventilation rate of $100 \mathrm{scfm}$ was predicted to be adequate to keep the hydrogen concentration below the $6,250 \mathrm{ppm}$ action limit for pumping rates up to $100 \mathrm{gpm}$. Mahoney revised gas release estimates to adjust for changes in retained gas inventory due to saltwell pumping of Tank S-112 but also used the relatively low estimate of retained gas inventory. ${ }^{\text {(b) }}$ Neither Stewart and Morrissette nor Mahoney addressed hydraulic erosion of the saltcake as a potentially significant impact on the gas release rate.

This report estimates a bounding, rather than best estimate, retrieval gas release rate by considering the conservative $95^{\text {th }}$ percentile retained gas volume fractions developed by Barker and Hedengren (2003). It also proposes and applies a bounding rate for the erosion of saltcake and estimates gas release rates accordingly.

\subsection{Organization of the Report}

Section 2 develops retained gas inventories, compositions, and flammability estimates for each tank studied in this report. Section 3 considers the mechanisms by which the retained gas could be released during retrieval by sluicing. Simple models to estimate gas release under different scenarios are developed and their results presented in Section 4. Section 5 discusses the results of the study, and Section 6 contains cited references. Derivation of the models is provided in the appendixes.

(a) Stewart CW and DJ Morrissette. September 2001. "Preliminary Assessment of Gas Releases at High Dissolution Rates in Tank 241-S-112." Letter Report TWS01.31 Rev. 1, Pacific Northwest National Laboratory, Richland, WA.

(b) Mahoney LA. November 2002. "Assessment of Gas Releases at High Retrieval Rates in Tank 241-S-112." Letter Report TWS03.016, Pacific Northwest National Laboratory, Richland, WA. 


\subsection{Retained Gas Inventories and Properties}

In this section, values for the retained gas inventory, composition, and flammability are developed for each tank considered in this report. Because the estimated inventories of retained flammable gases are to be used in subsequent analyses of safety-related scenarios, their development is intended to provide reasonably conservative values rather than most-probable or best-estimate values.

\subsection{Retained Gas Inventories and Composition}

The retained gas inventories of the waste tanks have been estimated by several techniques. Barometric pressure changes cause the retained gas in the waste to expand or compress, causing the waste surface level and/or the interstitial liquid level to fluctuate. The quantity of retained gas can be estimated from the magnitude of the level fluctuations (Whitney 1995). This technique is not applicable to all tanks because many have a solid waste surface that does not fluctuate with barometric pressure changes, and changes in interstitial liquid level below the surface cannot be measured with sufficient precision to be used.

Retained gas volumes from regions of selected waste tanks have been measured using a specially designed retained gas sampler. This also allows the composition of retained gases to be determined, but of the tanks of interest here, retained gas samples have been collected from only Tanks S-102 and S-106 (Mahoney et al. 1999), and the few measurements in each tank make estimating the total gas volume uncertain.

Vertical neutron probe logging of the waste, routinely conducted to measure the interstitial liquid level, has been analyzed to estimate waste void fraction and retained gas volumes. However, like the retained gas sampler, the neutron logs apply only to the immediate vicinity of the liquid observation well and are not necessarily representative of the entire tank.

Lastly, a gradual rise in the liquid level in a tank (either supernatant or interstitial liquid) is generally indicative of retained gas accumulation and can be used to estimate changes in the retained gas volume. Unfortunately, interstitial liquid level measurements were not available prior to about 1981, so any gases present in the waste before that time would not be included in such estimates.

In summary, a variety of methods have been used to estimate retained gas inventories with varying applicability and confidence in the results. Estimates of retained gas volumes determined from these sources as of December 2000 are compared in Hedengren et al. (2001).

The compositions and inventories of the retained gases in all 149 SSTs and 28 DSTs have recently been evaluated for the safety analysis by Barker and Hedengren (2003), who used a 
Monte Carlo simulation method to classify tanks based on their flammable gas release potential. They established probability distributions for the retained gas composition and gas volume fraction as input for the Monte Carlo simulations using all applicable retained gas volume and composition measurements. The hydrogen concentration of the retained gas is determined via the Monte Carlo simulation as a function of the other constituents. Table 2.1 lists selected values from these distributions for the tanks of interest. In this table the median value is that for which a higher or lower value is equally probable, and the $95^{\text {th }}$ percentile value is that for which a lower value is $95 \%$ probable. The electronic version of the files are available on CD from the authors of that report and are maintained by Nuclear Safety and Licensing under SafeSource.

Table 2.1. Retained Gas Distribution Data (Barker and Hedengren 2003)

\begin{tabular}{|c|c|c|c|c|c||}
\hline Tank & $\begin{array}{c}\text { Hydrogen } \\
\text { Median } \\
(\mathbf{v o l} \%)\end{array}$ & $\begin{array}{c}\text { Ammonia } \\
\text { Median } \\
\mathbf{( v o l \% )}\end{array}$ & $\begin{array}{c}\text { Methane } \\
\text { Median } \\
\mathbf{( v o l \% )}\end{array}$ & $\begin{array}{c}\text { Void Fraction } \\
\text { Median }\end{array}$ & $\begin{array}{c}\text { Void Fraction } \\
\mathbf{9 5}^{\text {th }} \text { percentile }\end{array}$ \\
\hline S-101 & 49.3 & 1.8 & 1.8 & 0.053 & 0.097 \\
\hline S-102 & 33.9 & 0.9 & 0.7 & 0.163 & 0.254 \\
\hline S-103 & 49.5 & 1.8 & 1.8 & 0.160 & 0.286 \\
\hline S-104 & 49.6 & 1.8 & 1.8 & 0.011 & 0.095 \\
\hline S-105 & 49.5 & 1.8 & 1.8 & 0.144 & 0.253 \\
\hline S-106 & 63.8 & 0.3 & 0.9 & 0.182 & 0.322 \\
\hline S-108 & 49.5 & 1.8 & 1.8 & 0.144 & 0.253 \\
\hline S-109 & 49.5 & 1.8 & 1.8 & 0.144 & 0.253 \\
\hline S-110 & 49.5 & 1.8 & 1.8 & 0.144 & 0.253 \\
\hline U-107 & 49.8 & 1.7 & 1.8 & 0.094 & 0.170 \\
\hline
\end{tabular}

In Table 2.1 the retained gas void fractions are the volume fractions of all gases (at the pressure and temperature the gas experiences) in the waste below the interstitial liquid level. Note that nitrogen $\left(\mathrm{N}_{2}\right)$ and nitrous oxide $\left(\mathrm{N}_{2} \mathrm{O}\right)$ constitute a significant portion of the retained gases (i.e., are included in the void fraction estimate) but are neither included in Table 2.1 nor discussed in detail because they are not flammable.

The void fraction distributions in Table 2.1 are based on specific tank measurements or, in the lack thereof, assigned by waste type (see Barker and Hedengren 2003). The gas volume inventory estimation techniques discussed previously may provide either the retained gas volume, from which the void fraction may be derived based on waste volumes, etc., or direct void fraction measurements. As such, depending on the measurement date, the void fraction distributions given in Table 2.1 may not include recent changes associated with the removal of interstitial liquid by saltwell pumping. Saltwell pumping decreases the region of waste wherein retained gases can reside. It also lowers the hydrostatic pressure experienced by the retained gas, causing it to expand, which in turn enhances the rate of upward bubble migration through the saltcake (Huckaby et al. 1999). Headspace hydrogen concentration monitoring data clearly show 
that saltwell pumping causes a significant fraction of retained gases to be released into the headspace (Huckaby et al. 1999). ${ }^{\text {(a) }}$

To maintain consistency with the safety documentation of Barker and Hedengren (2003) and serve as a bounding analysis, this study uses the $95^{\text {th }}$ percentile void fraction in Table 2.1 as the bounding value to calculate the current retained gas inventory. Recent waste changes due to saltwell pumping are accounted for by using the most up-to-date waste volume data. It is assumed that all the waste below the interstitial liquid level has a uniform retained gas void fraction and is subject to an average hydrostatic pressure, $P_{W}$, in inches of $\mathrm{H}_{2} \mathrm{O}$, which is estimated by the following expression:

$$
P_{W}=P_{H S}+\frac{1}{2} S p G h_{I L}
$$

where $P_{H S}$ is the tank headspace pressure in units of inches of $\mathrm{H}_{2} \mathrm{O}, S p G$ is the specific gravity of the interstitial liquid, and $h_{I L}$ is the initial interstitial liquid level in inches.

The current inventory of retained gas, $V_{G H S}$, at atmospheric pressure and headspace temperature can be calculated directly from the volume of waste below the interstitial liquid level, $V_{W<I L L}$, the void fraction, $\alpha$, the temperatures of the retained gas, $T_{W}$, and headspace, $T_{H S}$, the average hydrostatic pressure on the retained gas, $P_{W}$, and the headspace pressure, $P_{H S}$, using the following expression:

$$
V_{G H S}=\alpha V_{W<I L L} \frac{P_{W}}{P_{H S}} \frac{T_{H S}}{T_{W}}
$$

These equations allow the total retained gas inventory in a tank, at headspace conditions, to be calculated directly. Table 2.2 lists the parameter values and calculated retained gas volumes for each tank of interest in this study, assuming the $95^{\text {th }}$ percentile void fractions in Table 2.1.

In this report the concentrations of the three flammable species hydrogen, methane, and ammonia in the retained gas are assumed to be the median values given in Table 2.1. These median values, when combined with the median void fraction, would give the best-estimate inventories for each of these gases. The product of the $95^{\text {th }}$ percentile void fraction and the median concentrations from Table 2.1 would approximate the $95^{\text {th }}$ percentile values for the gas inventories. This level of conservatism has become the standard in waste tank safety calculations. Because the values and distributions of the void fraction are independent of (and mutually exclusive with) the values and distributions of the retained gas constituent concentrations, combining the $95^{\text {th }}$ percentile void fraction with the $95^{\text {th }}$ percentile retained gas

(a) See also: Peurrung LM and JL Huckaby. March 2000. "Gas Release Behavior During Salt-Well Pumping." Letter report TWS00.39, Pacific Northwest National Laboratory, Richland, WA. 
Table 2.2. Input Parameter Values and Calculated Retained Gas Inventories

\begin{tabular}{|c|c|c|c|c|c|c|c|}
\hline Tank & $\begin{array}{c}\text { Liquid } \\
S p G^{(\mathbf{a})}\end{array}$ & $\begin{array}{c}h_{I L 0}{ }^{(b)} \\
\text { (inches) }\end{array}$ & $\begin{array}{l}P_{W}^{(c)} \\
(\mathbf{a t m})\end{array}$ & $\begin{array}{l}T_{W}^{(\mathrm{d})} \\
(\mathbf{K})\end{array}$ & $\begin{array}{c}T_{H S}^{(\mathrm{e})} \\
(\mathbf{K})\end{array}$ & $\begin{array}{c}V_{W<I L L}^{(f)} \\
\text { (gal) }\end{array}$ & $\begin{array}{c}V_{G H S}{ }^{(\mathrm{g})} \\
\left(\mathbf{f t}^{3}\right)\end{array}$ \\
\hline S-101 & 1.47 & 123.5 & 1.223 & 313.6 & 304.7 & 314,757 & 4,856 \\
\hline S-102 & 1.46 & 172.4 & 1.309 & 307.4 & 298.4 & 449,262 & 19,389 \\
\hline S-103 & 1.45 & 92.2 & 1.164 & 298.9 & 296.6 & 228,369 & 10,094 \\
\hline S-104 & 1.37 & 111.7 & 1.188 & 309.1 & 302.3 & 282,072 & 4,167 \\
\hline S-105 & 1.44 & 54.7 & 1.097 & 296.7 & 294.3 & 125,028 & 4,591 \\
\hline S-106 & 1.43 & 54.6 & 1.096 & 295.7 & 292.9 & 124,897 & 5,840 \\
\hline S-108 & 1.44 & 63.3 & 1.112 & 299.4 & 294.7 & 148,988 & 5,504 \\
\hline S-109 & 1.49 & 67.4 & 1.123 & 299.6 & 293.1 & 160,059 & 5,938 \\
\hline S-110 & 1.43 & 130.5 & 1.229 & 313.8 & 299.0 & 333,990 & 13,207 \\
\hline U-107 & 1.43 & 75.9 & 1.133 & 296.6 & 295.0 & 183,556 & 4,714 \\
\hline
\end{tabular}

(a) Liquid SpG values are from the BBI.

(b) $h_{I L 0}$ is the initial interstitial liquid height. Values given are the most recently reported values on the TCD as of February 12, 2004.

(c) A unit conversion factor of $0.0024583 \mathrm{~atm} / \mathrm{in} . \mathrm{H}_{2} \mathrm{O}$ was applied to Eq. (2.1).

(d) Waste temperatures were calculated by averaging the TCD values for all thermocouples below the interstitial liquid level between February 18, 2003 and February 17, 2004.

(e) Headspace temperatures were calculated by averaging the TCD values for all thermocouples above the waste surface level between February 18, 2003 and February 17, 2004.

(f) Volumes of waste below the interstitial liquid levels were calculated using the $h_{I L}$ and algorithms given by Barker (2003).

(g) Calculated retained gas volumes are for $1 \mathrm{~atm}$ pressure and $T_{H S}$. Calculated values include a conversion factor of $0.13368 \mathrm{ft}^{3} / \mathrm{gal}$.

concentrations would give approximately the $99^{\text {th }}$ percentile values for the hydrogen, methane, and ammonia inventories, which are considered here to be excessively conservative.

\subsection{Flammability of Retained Gas Mixtures}

The LFL of a gas in a mixture is the lowest concentration that supports flame propagation away from the point of ignition. The LFL for upward flame propagation is typically used in safety analysis because it best represents the turbulent convective atmosphere of a tank headspace. LFLs for upward flame propagation in air of the three flammable species in the retained gas (hydrogen, methane, and ammonia) are 4, 5 and $15 \mathrm{vol} \%$, respectively. The flammability of a mixture of these three gases may be estimated using Le Chatelier's linear mixing law:

$$
L F L_{M I X}=\frac{1}{\sum_{i=1}^{n} \frac{C_{i}}{L F L_{i}}}
$$

where $L F L_{M I X}$ is the LFL in air of the mixture, and $C_{i}$ and $L F L_{i}$ are the volume fraction (i.e., concentration) and LFL of the $i^{\text {th }}$ fuel species. It is also required that 


$$
\sum_{i=1}^{n} C_{i}=1
$$

Table 2.3 lists the published LFLs for the individual gases used in this report. The LFL of the flammable gas mixture in each tank will be different because each tank has a different estimated retained gas composition. Using the median hydrogen, methane, and ammonia retained gas concentrations given in Table 2.1, the relative contributions of each gas [i.e., the $C_{i}$ of Eq. (2.3) and (2.4)] and the LFL of their mixture have been calculated and are listed in Table 2.4. As expected, the mixture LFLs are similar to that of hydrogen because the dominant flammable gas in each tank is hydrogen.

Table 2.3. LFL in Air of Flammable Retained Gases

\begin{tabular}{|c|c||}
\hline Constituent & $\begin{array}{c}\text { LFL in air } \\
\text { (volume fraction) }\end{array}$ \\
\hline Hydrogen & 0.04 \\
\hline Methane & 0.05 \\
\hline Ammonia & 0.15 \\
\hline (a) LFL values for individual species are from Zabetakis (1965). \\
\hline
\end{tabular}

Table 2.4. LFL in Air of Retained Gas Mixtures by Tank

\begin{tabular}{|c|c|c|c|c|}
\hline Tank & $\begin{array}{c}\text { Fraction of } \mathrm{H}_{2} \text { in } \\
\text { flammable portion, } \\
C_{H 2}\end{array}$ & $\begin{array}{l}\text { Fraction of } \mathrm{CH}_{4} \text { in } \\
\text { flammable portion, } \\
C_{C H 4}\end{array}$ & $\begin{array}{c}\text { Fraction of } \mathrm{NH}_{3} \text { in } \\
\text { flammable portion, } \\
C_{N H 3}\end{array}$ & $\begin{array}{c}\text { Flammability in air, } \\
L F L_{M I X} \\
\text { (volume fraction) }\end{array}$ \\
\hline S-101 & 0.933 & 0.034 & 0.033 & 0.0413 \\
\hline S-102 & 0.954 & 0.019 & 0.026 & 0.0409 \\
\hline S-103 & 0.933 & 0.034 & 0.033 & 0.0413 \\
\hline S-104 & 0.932 & 0.035 & 0.033 & 0.0413 \\
\hline S-105 & 0.932 & 0.034 & 0.033 & 0.0413 \\
\hline S-106 & 0.982 & 0.013 & 0.005 & 0.0402 \\
\hline S-108 & 0.932 & 0.034 & 0.033 & 0.0413 \\
\hline S-109 & 0.932 & 0.034 & 0.033 & 0.0413 \\
\hline S-110 & 0.932 & 0.034 & 0.033 & 0.0413 \\
\hline $\mathrm{U}-107$ & 0.933 & 0.034 & 0.033 & 0.0413 \\
\hline
\end{tabular}

\subsection{Flammability of Released Gases}

In addition to the inventory, composition, and flammability of the retained gases in each tank, the potential for the tank headspace to reach a flammable condition also depends on the headspace volume. Table 2.5 summarizes the tank parameters needed to calculate whether the headspace could reach a flammable condition and gives the calculated headspace flammability as a percentage of the LFL. As indicated in Table 2.5, Tank S-102 would have the highest headspace flammability if all the retained gas estimated in Table 2.2 were released instantaneously. 
Table 2.5. Calculated Headspace Flammability by Tank if All Retained Gas Were Released into the Tank Headspace Instantaneously

\begin{tabular}{|c|c|c|c|c|c|}
\hline Tank & $\begin{array}{c}\text { Waste Volume }^{(a)} \\
\text { (kgal) }\end{array}$ & $\begin{array}{c}\text { Headspace } \\
\text { Volume }^{(\mathbf{b})} \\
\left(\mathbf{f t}^{3}\right)\end{array}$ & $\begin{array}{c}\text { Flammable } \\
\text { Fraction of } \\
\text { Retained Gas }^{(\mathfrak{c})}\end{array}$ & $\begin{array}{c}\text { Flammable } \\
\text { Retained Gas } \\
\text { Volume }^{(\mathbf{d})} \\
\left(\mathbf{f t t}^{3}\right)\end{array}$ & $\begin{array}{c}\text { Headspace } \\
\text { Flammability } \\
\text { (\% of LFL) }\end{array}$ \\
\hline S-101 & 351 & 93,440 & 0.528 & 2,566 & 67 \\
\hline S-102 & 498 & 73,789 & 0.355 & 6,890 & 228 \\
\hline S-103 & 238 & 108,546 & 0.530 & 5,350 & 119 \\
\hline S-104 & 288 & 101,862 & 0.533 & 2,220 & 53 \\
\hline S-105 & 406 & 86,088 & 0.531 & 2,439 & 69 \\
\hline S-106 & 455 & 79,537 & 0.649 & 3,791 & 118 \\
\hline S-108 & 550 & 66,838 & 0.531 & 2,924 & 106 \\
\hline S-109 & 533 & 69,110 & 0.531 & 3,154 & 111 \\
\hline S-110 & 389 & 88,360 & 0.531 & 7,015 & 192 \\
\hline U-107 & 294 & 74,250 & 0.534 & 2,516 & 82 \\
\hline \multicolumn{6}{|c|}{$\begin{array}{l}\text { (a) Waste volumes from Hanlon (2004) with the exception of that for Tank S-102. Tank S-102 waste and initial } \\
\text { headspace volumes have been adjusted to include the approximately } 60 \mathrm{kgal} \text { of drained waste not currently included } \\
\text { in the BBI (see Appendix A). } \\
\text { (b) Calculated by subtracting waste volumes from empty tank volumes. All } 241-\mathrm{S} \text { farm tanks have an empty tank } \\
\text { volume of } 140,362 \mathrm{ft}^{3} \text {, and U-107 has an empty tank volume of } 113,552 \mathrm{ft}^{3} \text { (Barker } 2003 \text { ). } \\
\text { (c) Calculated by summing individual gas median volume fractions in Table } 2.1 \text {. } \\
\text { (d) Values are at average tank headspace temperature and } 1 \text { atm pressure. Calculated by multiplying values in } \\
\text { fourth column by } V_{\text {gas }} \text { values from Table } 2.2 \text {. }\end{array}$} \\
\hline
\end{tabular}




\subsection{Retained Gas Release Mechanisms}

Three mechanisms have been identified for the release of gases retained in the waste during modified sluicing retrieval of the waste. Retained gases will be released by drainage of the interstitial liquid from the undisturbed solid matrix, dissolution of the saltcake solid matrix, and hydraulic erosion of the solid matrix with water jets.

\subsection{Supernatant and Interstitial Liquid Removal}

The removal of liquids from a waste tank can induce the release of retained gases by decreasing the hydrostatic pressure on the retained gas and by uncovering retained gas bubbles. Independent of whether the liquid is supernatant or interstitial, the removal of liquid reduces the hydrostatic head on the retained gas. This causes the gas to expand, the bubbles of retained gas to grow larger, and the rate of their upward migration to increase (Stewart et al. 1996). Some bubbles that had been essentially immobilized in the solid matrix by surrounding liquid will become large enough to start their migration upward. Once the supernatant liquids have been removed from a tank interstitial liquid drainage also uncovers bubbles, allowing the gas to diffuse upward through the porous matrix to the headspace.

Headspace hydrogen concentration data collected during saltwell pumping have indicated that the rate of retained gas release is approximately proportional to the interstitial liquid drainage rate..$^{\text {(a) }}$ This is consistent with the retained gases existing in the interstices of the saltcake as small bubbles separated and trapped by the interstitial liquid. To a first approximation, the fraction of retained gas released by gravitational drainage is equal to the fraction of interstitial liquid drained. For example, if half the interstitial liquid in a region of waste is drained, about half the retained gas in that region of waste will be released.

The rate at which interstitial liquid can be drained to a central well depends on the permeability of the waste, the height of the interstitial liquid in the waste, and the depth of liquid in the central well. Consequently, the drainage rates during the retrieval operations will vary with spatial variations in the waste and changes in the size, shape, and depth of the central pool around the retrieval pump. Given that modified sluicing has only been initiated on one tank and many key waste characteristics are not known, these factors can not be predicted reliably. However, consideration of the extended time (months) required to drain interstitial liquid during saltwell pumping of saltcake tanks suggests that this process is slower than the planned retrieval rate. For example, during the September and October 2002 saltwell pumping of Tank S-112, the maximum sustained pumping rate (which is limited by and thus approximately equivalent to the drainage rate) was about $1.5 \mathrm{gpm}^{\text {(b) }}$ By contrast, the erosion and dissolution of waste during retrieval operations is expected to allow a nominal retrieval pumping rate of $80 \mathrm{gpm}$.

(a) Peurrung LM and JL Huckaby. March 2000. "Gas Release Behavior During Saltwell Pumping." Letter report TWS00.39, Pacific Northwest National Laboratory, Richland, WA.

(b) On September 22, 2002, an estimated 1,758 gal of waste liquids were pumped from Tank S-112 over a 19.8hour period. By the following day the drainage rate had dropped, limiting the pumping rate to about $0.55 \mathrm{gpm}$. 


\subsection{Dissolution of the Solid Waste Matrix}

The dissolution of the gas-bearing saltcake matrix will release the gases trapped in the saltcake. Though the rate of saltcake dissolution during waste retrieval has yet to be established, it is inherently limited by the water application rate. An upper bound on the rate of gas release can be obtained by assuming that the water applied to the waste becomes instantaneously saturated and releases all the gases trapped in the saltcake it dissolves.

If dissolution is slow relative to water addition, the amount of water (or unsaturated brine) in the tank may be increased to increase the liquid residence time in the tank. In this event, the amount of water in the tank could be enough to dissolve saltcake and release enough flammable gas to raise the headspace to a flammable condition. Thus gas releases due to dissolution can be both a rate issue and a tank water inventory issue. Both issues are considered in Section 4.

\subsection{Hydraulic Erosion of the Solid Waste Matrix}

Retained gases will also be released when water jets are applied to erode the solid waste matrix hydraulically. Hydraulic erosion will depend on the force of the impacting water, the shear strength of the saltcake matrix, and other factors such as the shape of the surface. Attempts to estimate the erosion rate given the waste shear strength, initial power of the water jet, power losses, and inefficiencies have been unsuccessful due to a lack of relevant experimental data. In lieu of suitable erosion rate data, an upper bound on the rate of erosion can be established by realizing that the rate of erosion is effectively limited by the rate at which solids can be fluidized and carried away by the liquid. Sustained erosion of saltcake will require the removal of solids from the point where the jet impacts the saltcake or the jet will not impinge on undisturbed saltcake and erosion will be reduced. Thus erosion can occur no faster than the loosened solids are removed by the liquid.

To bound the rate at which solids can be removed by liquid, it is assumed that the impact of water on the saltcake could result in a slurry containing at most $30 \mathrm{wt} \%$ solids. This is a relatively high solids loading for slurry given that solid saltcake itself has a high liquid content. For comparison, a composite of core sample 292 from Tank S-112 which included sample from the well-drained waste above the interstitial liquid level, was estimated to have only about 64 wt $\%$ solids. ${ }^{\text {(a) }}$ The settled salt slurry in a typical double-shell tank contains less than $20 \mathrm{wt} \%$ solids. Visual observation (via headspace video cameras) of the S-112 waste surface during retrieval suggested that while a $30 \mathrm{wt} \%$ solids loading might be achievable, that erosion rate could not be sustained for more than a few minutes at a time.

(a) Core composite liquid content was based on analyses of water content and the aqueous phase chloride, nitrite, and cesium-137 constituents. Personal communication, Lenna Mahoney, PNNL, March 2003. 


\subsection{Models for Gas Release Rates and Headspace Flammability}

This section develops simple models to estimate gas releases under various scenarios, applies the models to the conservative flammable gas inventories developed in Section 2, and presents the tank-specific results. The models are based on assumptions and inputs chosen to ensure that results overstate, rather than understate, the probability of a flammable tank headspace.

\subsection{Gas Release Model Description}

A simple model was developed to estimate flammable gas release rates during the modified sluicing retrieval operations. The model is based on the following assumptions:

1. Water applied to the waste instantaneously dissolves its capacity of salt (i.e., the water is instantaneously saturated).

2. Saltcake erosion occurs at a rate that produces a slurry with $30 \mathrm{wt} \%$ solids in fully saturated brine.

3. The waste below the interstitial liquid level has a uniform retained gas void fraction, and no retained gas exists above the interstitial liquid level.

4. When the waste is being retrieved with a center-out approach, water is applied to the waste above and below the interstitial liquid level in proportion to the volumes of these two waste regions.

5. Gas releases due to interstitial liquid drainage (Section 3.1) are negligible compared with the gas releases due to waste erosion and dissolution. A rigorous accounting for gas releases associated with drainage would result in a corresponding decrease in gas releases due to erosion and dissolution, and its effect on the results would not be significant compared with the uncertainty inherent in the calculations.

6. The waste porosity (liquid volume fraction + gas volume fraction) is a nominal 0.50 throughout the waste in each tank.

The derivation of an expression for the gas release rate is presented in Appendix B, and only the result is presented here. Given the assumptions listed above, the volume of retained gas released per volume of water applied can be expressed as

$$
Q_{G A S}=\gamma V_{B} Q_{H 2 O}\left(\frac{P_{W}}{P_{H S}}\right)\left(\frac{T_{H S}}{T_{W}}\right)
$$

where $\gamma$ is the average retained gas void fraction in the waste being retrieved (retained gas as opposed to,$V_{B}$ is the volume of bulk waste disturbed per volume of water applied, and $Q_{H 2 O}$ is 
the volumetric water application rate. Note that the volumetric gas release rate, $Q_{G A S}$, in Eq. (4.1) is at headspace pressure, $P_{H S}$, and headspace temperature, $T_{H S}$.

The average gas volume fraction $\gamma$ deserves some clarification. Flammable gas is released only from previously undisturbed waste. The gas occupying the open pore space in drained waste is assumed to be air from the headspace. Therefore, if the dissolution water jets are directed only at previously undisturbed waste below the interstitial liquid level, $\gamma=\alpha$, the retained gas volume fraction. However, if the water is being directed at the waste both above and below the interstitial liquid level, then it is assumed that $\gamma=\alpha \frac{V_{W<I L L}}{V_{T}}$.

The volume of bulk waste disturbed per volume of water applied, $V_{B}$, is given by

$$
V_{B}=\frac{M_{D S}+F}{M_{S}-F\left(M_{S}+M_{I L}\right)}
$$

where $M_{D S}$ is the mass of dissolved solids per volume of water applied, $F$ is the specified mass fraction of undissolved solids in the product stream (e.g., 0.3 for a $30 \mathrm{wt} \%$ solids loading), $M_{S}$ is the mass of solids per bulk waste volume, and $M_{I L}$ is the mass of interstitial liquid per bulk waste volume. The quantities $M_{D S}, M_{S}$, and $M_{I L}$ can be calculated from waste properties and dissolution parameters via the following expressions:

$$
\begin{gathered}
M_{D S}=\beta_{L C} \rho_{B R}-\rho_{W} \\
M_{S}=\frac{\rho_{S} V_{S}}{V_{T}} \\
M_{I L}=\frac{\rho_{I L} V_{I L}}{V_{T}}
\end{gathered}
$$

where $\beta_{L C}$ is the volume of brine created by dissolution per volume of water added; $\rho_{B R}, \rho_{W}, \rho_{S}$, and $\rho_{I L}$ are the saturated brine, water, bulk solid, and interstitial liquid densities, respectively; and $V_{S}$ is the total volume of dry void-free solids in the tank.

Note that the only parameters in Eq. (4.1) through (4.5) that depend on the dissolution properties of the waste are $\beta_{L C}$ (the volume of brine created by dissolution per volume of water added) and $\rho_{B R}$ (the saturated brine density).

\subsection{Gas Release Model Inputs and Results}

The retained gas release rates for each tank of interest can be estimated using Eq. (4.1) through (4.5) with suitable waste properties and dissolution parameters. Total waste volume, $V_{T}$, 
for each tank is given in Table 2.5. Interstitial liquid densities, waste volume below the interstitial liquid level, $V_{W<I L L}$, and retained gas inventory, $V_{G}$, are given in Table 2.2 for each tank. ${ }^{\text {(a) }}$ The volumes of (dry, void-free) solid waste, $V_{S}$, and interstitial liquid, $V_{I L}$, are not well established for any of the tanks but are related to $V_{T}$ and $V_{G}$ using the waste porosity, $\phi$, by the following expressions:

$$
\begin{gathered}
V_{S}=(1-\phi) V_{T} \\
V_{I L}=\phi V_{W<I L L}-V_{G H S}
\end{gathered}
$$

These parameters were evaluated by assuming the waste porosity has a nominal value of 0.5 , as specified in Section 4.1.

To calculate gas release rates for each tank of interest, values must be established for the waste physical property, $\rho_{S}$ (solids density), and the two waste dissolution properties, $\beta_{L C}$ (the volume of brine created by dissolution per volume of water added) and $\rho_{B R}$ (the saturated brine density). For establishing retrieval safety guidelines, it is assumed these parameters are approximately the same for the tanks of interest here, and the values are those established for Tank S-112 by Cowin et al. (2003). Table 4.1 lists the parameter values and their sources. This should be reasonably conservative for calculating gas release rates for the following reasons:

- Among tank composite waste samples that have been tested, those from S-112 were found to be the most highly soluble in water (Herting and Edmonson 1998; Herting $1999,2000,2001,2002)$. This equates to a relatively high value for $\beta_{L C}$ and a correspondingly high value for the gas release rate, $Q_{R G}$.

- The high solubility of S-112 waste is directly associated with its high $\mathrm{NaNO}_{3}$ and low sludge contents (Cowin et al. 2003). These characteristics result in a relatively low average solids density, $\rho_{S}$, a high brine density, $\rho_{B R}$, and a correspondingly high value for the gas release rate, $Q_{R G}$.

Table 4.1. Tank Waste Dissolution Parameters

\begin{tabular}{|l|c|c|c||}
\hline \multicolumn{1}{|c|}{ Parameter } & Symbol & Value & Source \\
\hline Density of dry (void-free) solids $(\mathrm{kg} / \mathrm{L})$ & $\rho_{S}$ & 2.25 & Cowin et al. (2003), Table B-2 \\
\hline Volume of brine created per volume of water applied & $\beta_{L C}$ & 1.334 & Cowin et al. (2003) Table B-3 \\
\hline Density of brine created $(\mathrm{kg} / \mathrm{L})$ & $\rho_{B R}$ & 1.44 & Cowin et al. (2003) Table B-2 \\
\hline
\end{tabular}

(a) Specific gravity $(S p G)$ values given in Table 2.2 are equal to density in units of $\mathrm{kg} / \mathrm{L}$. 
Retained gas release rates calculated with Eq. (4.1) through (4.7) and values from Tables 2.2, 2.5, and 4.1 for the nominal 80-gpm water application rate are listed in Table 4.2. Values given in Table 4.2 are for the scenario of dissolution water jets directed at only gas-bearing waste below the interstitial liquid level $(\gamma=\alpha)$, and therefore represent the maximum gas release rates. Also given in Table 4.2 is the flammable gas release rate, $Q_{F G}$, calculated by multiplying the retained gas release rate by the fraction of flammable gas in the retained gas of each tank given in Table 2.5.

Table 4.2. Maximum Gas Release Rates by Tank for 80 gpm Water Application Rate

\begin{tabular}{|c|c|c|c|c|}
\hline Tank & $\begin{array}{c}\text { Retained Gas } \\
\text { Release Rate, } \\
Q_{G A S} \\
\left(\mathbf{f t}^{3} / \mathbf{m i n}\right) \\
\end{array}$ & $\begin{array}{l}\text { Flammable Gas } \\
\text { Release Rate, } Q_{F G} \\
\left(\mathrm{ft}^{3} / \mathrm{min}\right)\end{array}$ & $\begin{array}{c}\text { Rate of Change in \% } \\
\text { of LFL in Headspace } \\
\text { (\% of LFL/hr) }\end{array}$ & $\begin{array}{c}\text { Time to Reach LFL } \\
\text { (hr) }\end{array}$ \\
\hline S-101 & 2.4 & 1.3 & $2.0 \%$ & 50.7 \\
\hline S-102 & 6.1 & 2.2 & $4.3 \%$ & 23.2 \\
\hline S-103 & 6.2 & 3.3 & $4.4 \%$ & 22.8 \\
\hline S-104 & 2.3 & 1.2 & $1.8 \%$ & 57.0 \\
\hline S-105 & 4.8 & 2.5 & $4.3 \%$ & 23.5 \\
\hline S-106 & 6.0 & 3.9 & $7.3 \%$ & 13.8 \\
\hline S-108 & 4.8 & 2.5 & $5.5 \%$ & 18.2 \\
\hline S-109 & 4.8 & 2.6 & $5.4 \%$ & 18.6 \\
\hline S-110 & 5.5 & 2.9 & $4.8 \%$ & 20.6 \\
\hline U-107 & 3.6 & 1.9 & $3.7 \%$ & 26.7 \\
\hline
\end{tabular}

The model developed for gas release rates can be extended to estimate the increase in headspace flammability as a function of the flammable gas release rate, the flammability of the released gases (i.e., the LFL of the retained gas mixture), and the headspace volume. The change in headspace flammability, expressed as a percent of the LFL of the tank headspace, is given by the expression

$$
\text { Rate of change in headspace flammability }=\frac{Q_{F G}}{V_{H S} L F L_{M I X}} \times 100 \%
$$

where $V_{H S}$ is the headspace volume (see Table 2.5). The calculated rate of change in headspace flammability for each tank is given in the last column of Table 4.2. Note that these values are based on the current headspace volume estimates and should decrease as waste is removed and the headspace volume increases. Note also that the results given in Table 4.2 take no credit for ventilation of the headspace, and in this respect represent the worst-case scenario results.

\subsection{Model Extended for Ventilation of Headspaces}

The model given by Eq. (4.1) through (4.8) allows the estimation of the retained gas release rates and potential increases in headspace flammability during the modified sluicing retrieval of 
saltcake wastes. It is adequate and appropriate, with allowance for the specified assumptions, for calculating the increase in headspace flammability when it can be assumed that both ventilation and changes in the headspace volume are negligible. To examine the effects of ventilation on the headspace flammability, the gas release rate model has been combined with a simple model for tank headspace gas concentrations.

The headspace concentration of a gas is relatively easily modeled if it can be assumed that the gas is well mixed within the headspace. This is generally a good assumption in passively ventilated tank headspaces, because thermally induced convection currents mix the headspace. ${ }^{\text {(a) }}$ Stronger mixing is expected in actively ventilated tanks because thermal convection currents are augmented by convection due to the flow of air into and out of the headspace. It is therefore assumed that retained gases released into the headspace are instantaneously mixed within the headspace. The equations describing the headspace concentration of a gas under this assumption are developed in Appendix C. The general equation for the gas concentration, $C_{H}$, at time $t_{2}$ is

$$
C_{H}\left(t_{2}\right)=\frac{Q_{G A S} \chi_{H}}{Q_{A}}+\left(\left(C_{H}\left(t_{1}\right)-\frac{Q_{G A S} \chi_{H}}{Q_{A}}\right)\left(\frac{V_{H S 0}-Q_{B} t_{2}}{V_{H S 0}-Q_{B} t_{1}}\right)^{\frac{Q_{A}}{Q_{B}}}\right.
$$

where $\chi_{H}$ is the volume fraction of the gas in the retained gas, $V_{H S O}$ is the headspace volume at time zero, and $C_{H}\left(t_{1}\right)$ is the concentration of the gas at time $t_{1}$. The quantities $Q_{A}$ and $Q_{B}$ are defined to be

$$
\begin{gathered}
Q_{A}=Q_{V O U T}-Q_{W I N}+Q_{B O U T}+Q_{G A S} \frac{P_{H S}}{P_{W}} \\
Q_{B}=Q_{W I N}-Q_{B O U T}-Q_{G A S} \frac{P_{H S}}{P_{W}}
\end{gathered}
$$

where $Q_{\text {VOUT }}$ is the volumetric flow of air out via the ventilation system (i.e., exhaust rate), $Q_{B O U T}$ is the volumetric flow of waste out via the retrieval pump, and $Q_{W I N}$ is the volumetric flow of water into the tank (i.e., dissolution/erosion water). Air is assumed to flow into the headspace at a rate that balances the addition of water, the removal of waste, the gas release rate, and the air exhaust rate.

(a) The waste surface is generally warmer than the tank walls and dome because radioactive decay within the waste produces heat that must be carried away. Headspace air warmed by contact with the waste surface becomes buoyant and rises, then, cooled by contact with the tank dome and walls, cools and sinks. Huckaby et al. (1997) examined mixing in a passively ventilated SST and found an injected gas essentially completely mixed within about an hour. 


\subsection{Model Results for Ventilated Headspaces}

The model consisting of Eq. (4.1) through (4.11) was applied to examine headspace concentrations of the flammable gas portion of the retained gas as a function of time. Figure 4.1 illustrates the results for Tank S-102 for various ventilation rates. In this figure the nominal water application and retrieval pump rates are both $80 \mathrm{gpm}$, and the saturated brine leaving the point of water jet impact is assumed to have a $30 \mathrm{wt} \%$ solids loading. The curves in Figure 4.1 are for the scenario of dissolution water jets directed at only gas-bearing waste below the interstitial liquid level $(\gamma=\alpha)$ and therefore represent the maximum gas release rates (consistent with Table 4.2). Low ventilation rates, such as those that occur when the headspace is passively ventilated, are shown in Figure 4.1 to have only a small effect on the rise of headspace flammability. The curves in Figure 4.1 correspond to nil $(0 \mathrm{cfm})$, a relatively high passive ventilation rate $(15 \mathrm{cfm}),{ }^{(a)}$ a low active ventilation rate $(300 \mathrm{cfm})$, the nominal active ventilation rate $(450 \mathrm{cfm})$, and a maximum active ventilation rate $(500 \mathrm{cfm}){ }^{(\mathrm{b})}$

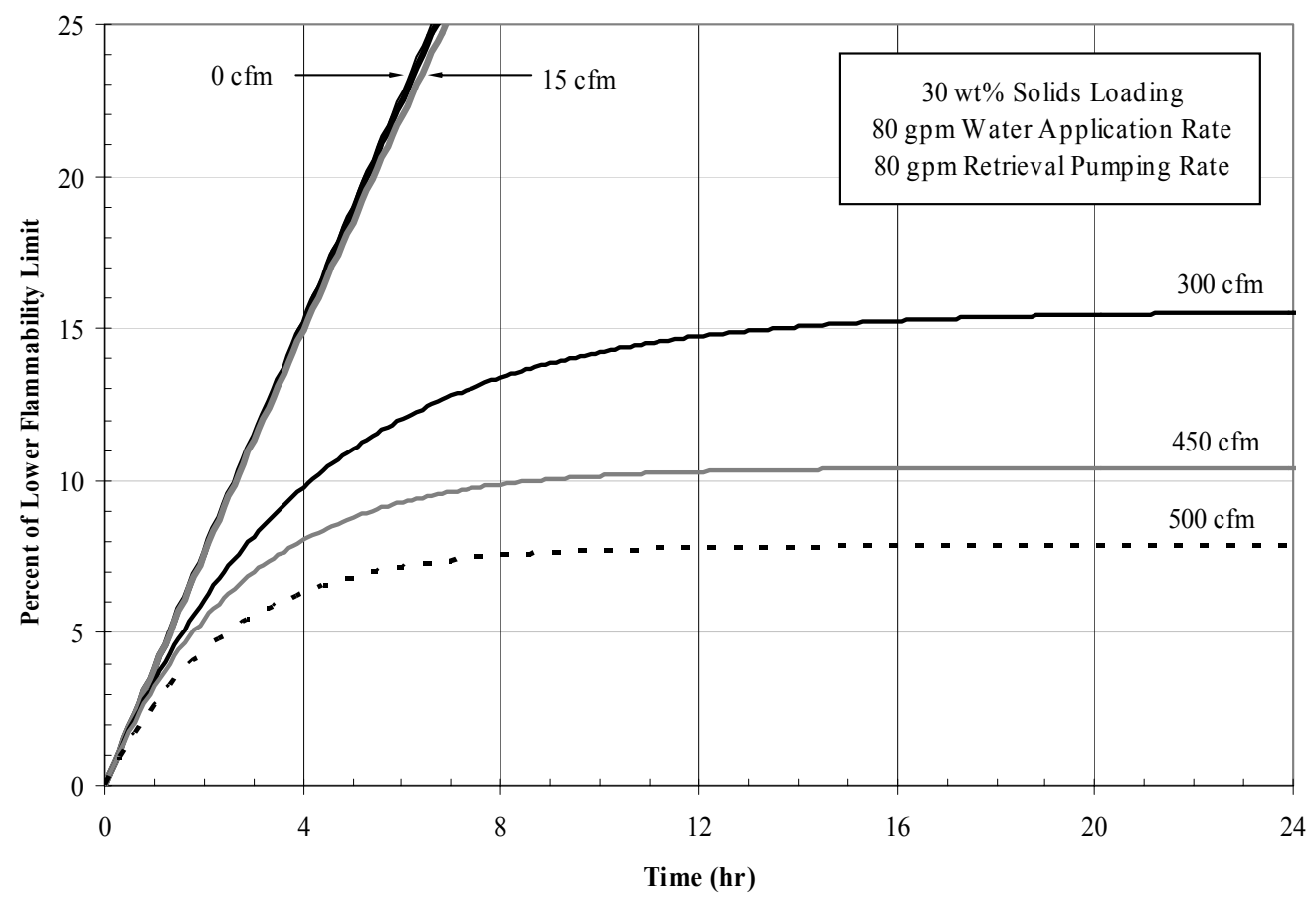

Figure 4.1. Tank S-102 Headspace Flammability as a Function of Time for Various Ventilation Rates

(a) Passive ventilation rates vary with time and can vary significantly among tanks. Higher rates are typically associated with better/larger connections with adjacent tanks and the atmosphere (Huckaby et al. 1998). The nominal value of $5 \mathrm{cfm}$ is consistent with other safety analyses (Hu and Barker 2002) and agrees well with the $4.5 \mathrm{cfm}$ value calculated from headspace hydrogen monitoring data by Mahoney (see footnote b, p.1.4). The average passive ventilation rate during retrieval will probably be significantly higher due to the second filtered pathway.

(b) The S-112 retrieval portable exhauster was set to run at $450 \mathrm{cfm}$ and has a maximum flow rate of about $500 \mathrm{cfm}$. 
The initial slope of each curve is the same $(4.3 \%$ of LFL/hr) (see Table 4.2$)$, but then the curves deviate from this, with higher ventilation rates causing the most dramatic deviations. The headspace flammability values at the three highest ventilation rates have essentially reached a pseudo-steady state within the first day. At its nominal rate of $450 \mathrm{cfm}$, the headspace hydrogen concentration reaches a pseudo-steady-state value of approximately $10.4 \%$ of the LFL. Changes in the retrieval pumping rate have only a small effect on the pseudo-steady-state headspace flammability values. For example, when the ventilation rate is assumed to be $450 \mathrm{cfm}$, increasing the retrieval pumping rate from 80 to $120 \mathrm{gpm}$ changes the pseudo-steady-state headspace flammability from 10.5 to $10.4 \%$ of the LFL, and decreasing the retrieval pumping rate to $50 \mathrm{gpm}$ changes the value to $10.6 \%$ of the LFL.

Plots of headspace flammability as a function of time for the other tanks are very similar in appearance to Figure 4.1 for Tank S-102. Figure 4.2 presents results for six tanks assuming the nominal ventilation rate of $450 \mathrm{cfm}$. The tanks selected include the tank with the highest pseudo-steady-state headspace flammability, Tank S-103, and the tank with the lowest pseudosteady-state headspace flammability, Tank S-108. Though tanks with smaller headspaces (e.g., S-102) approach their pseudo-steady-state conditions faster than tanks with larger headspaces (e.g., S-103), the pseudo-steady-state headspace flammability value is not affected by headspace volume.

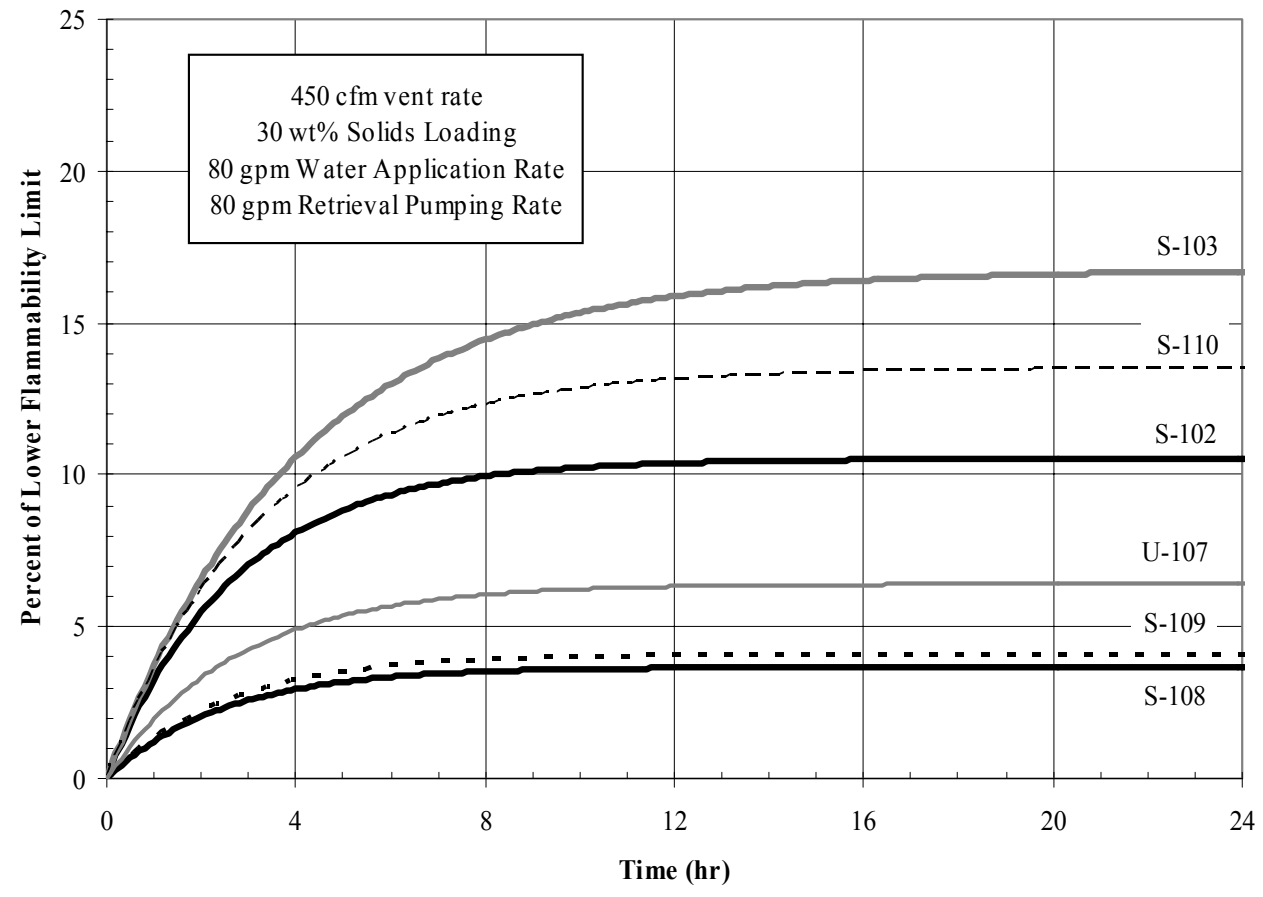

Figure 4.2. Headspace Flammability as a Function of Time for Several Tanks Given a Ventilation Rate of $450 \mathrm{cfm}$ 


\subsection{Gas Releases During Process Shutdowns}

The model described in the preceding sections was developed to obtain reasonably conservative estimates of the flammable retained gas release rates in the tanks of interest. It supposes very aggressive waste retrieval rates (e.g., instantaneous saturation of applied water plus erosion leading to $30 \mathrm{wt} \%$ solids loading) and assumes that all retained gases in the affected waste are released. Gas release rates are consequently tied to the application of water, and it is tacitly assumed that if the application of water were stopped, gas releases would also stop. However, some continued release of retained gases is inevitable and must be considered a potential safety hazard.

It is assumed that the worst-case condition is one in which both the retrieval pump and the ventilation system are simultaneously shut down, and that the headspace at that time is at $25 \%$ of the LFL. It is also assumed that, upon loss of the retrieval pump, all water application is stopped within a relatively short time, and that the gas released during that short time is negligible. Once water application has been stopped, two phenomena can cause the continued release of retained gases. First, if the liquid level in the central pool is lower than the interstitial liquid level, drainage of interstitial liquid will release gases from the surrounding saltcake. Second, if a large quantity of water has been added to the tank just before the process shutdown, this water would eventually dissolve saltcake and release any retained gases it contained. These two scenarios are considered separately below.

\subsubsection{Liquid Drainage after Process Shutdown}

Consider the scenario of a partially-retrieved waste tank having an open central pit as depicted in Figure 1.1. With the water application and retrieval pumps shut down, the drainage of interstitial liquid from the surrounding ring of saltcake will release retained gases in the drained waste and gradually fill the central pit with liquid. Clearly, the greatest drainage and associated gas releases will occur if the central pit is initially empty. Drainage (and gas releases) stop when the interstitial liquid level has dropped to the same level as the surface of the central pool. The height of the interstitial liquid at that point is given by

$$
h_{I L^{*}}=\frac{h_{P O O L 0}+h_{I L}(\phi-\alpha)\left(\frac{R^{2}}{r^{2}}-1\right)}{1+(\phi-\alpha)\left(\frac{R^{2}}{r^{2}}-1\right)}
$$

where $h_{P O O L O}$ is the initial height of liquid in the central pool, $h_{I L}$ is the initial height of interstitial liquid, $R$ is the radius of the tank, $r$ is the effective radius of the central pit (assumed to be approximately a cylinder), and $\phi$ and $\alpha$ are the waste porosity and retained gas void fraction, respectively. Lowering the interstitial liquid level to $h_{I L^{*}}$ will, as discussed in Section 3.1, 
release some of the gases trapped in the region between $h_{I L}$ and $h_{I L^{*}}$ and reduce the hydrostatic pressure on the retained gases that remain below $h_{I L^{*}}$. Conservatively assuming that all the interstitial liquid is drained (and therefore all the retained gas is released) from the waste between $h_{I L}$ and $h_{I L^{*}}$ and that the expansion of gases below $h_{I L^{*}}$ has resulted in a new retained gas inventory based on the original void fraction at the decreased hydrostatic pressure $P_{W^{*}}$, the total volume of gas released by the drainage is given by

$$
\Delta V_{G A S}=\alpha\left(1-\frac{r^{2}}{R^{2}}\right)\left(\frac{T_{H S}}{P_{H S}}\right)\left\{V_{W<I L L}\left(\frac{P_{W}}{T_{W}}\right)-\left[V_{W<I L L}-\pi R^{2}\left(h_{I L}-h_{I L^{*}}\right)\left(\frac{P_{W^{*}}}{T_{W^{*}}}\right)\right\}\right.
$$

where $T_{W^{*}}$ is the average temperature of the retained gas after drainage. Appendix B provides the derivation of Eq. (4.12) and (4.13).

In terms of headspace flammability, the release of $\Delta V_{G A S}$ retained gas will raise the headspace flammability by

$$
\text { Change in headspace flammability }=\frac{\lambda \Delta V_{G A S}}{V_{H S^{*}} L F L_{M I X}} \times 100 \%
$$

where $\lambda$ is the fraction of retained gas that is flammable and $V_{H S^{*}}$ is the new headspace volume. As indicated by these equations, the eventual height of the interstitial liquid, $h_{I L^{*}}$, the volume of retained gas released by drainage, and the change in headspace flammability are each functions of the central pit radius, $r$.

Eq. (4.14) was applied to estimate the potential change in headspace flammability due to drainage for each tank of interest. Tank headspace volumes, $V_{H S^{*}}$, were calculated for each tank by adjusting the initial headspace volume for the cylinder of air between the surface of the central pool and the initial waste surface, and $T_{W^{*}}$ was assumed to be equal to $T_{W}$. Figure 4.3 plots the change in headspace flammability due to liquid drainage as a function of $r$ for all 10 tanks. The tanks are listed in the legend of Figure 4.3 in order of decreasing curve maxima. For example, the dashed curve with the greatest maximum is for Tank S-102, the solid curve just below it is for Tank S-101, and the lowest curve is for Tank S-104. Results for Tanks S-108 and S-109 are almost identical and essentially trace a single curve in Figure 4.3.

The results depicted in Figure 4.3 suggest that if the retrieval process is being controlled to maintain the tank headspace at or below $25 \%$ of the LFL and the central pool was effectively drained when all headspace ventilation is lost, subsequent drainage of liquids in two of the tanks (S-102 and S-110) could potentially release enough gas to raise the headspaces of these tanks above $100 \%$ of the LFL. However, note that the potential for a $75 \%$ of the LFL rise exists for only a limited range of the effective central pool radius. Drainage of interstitial liquid when the 


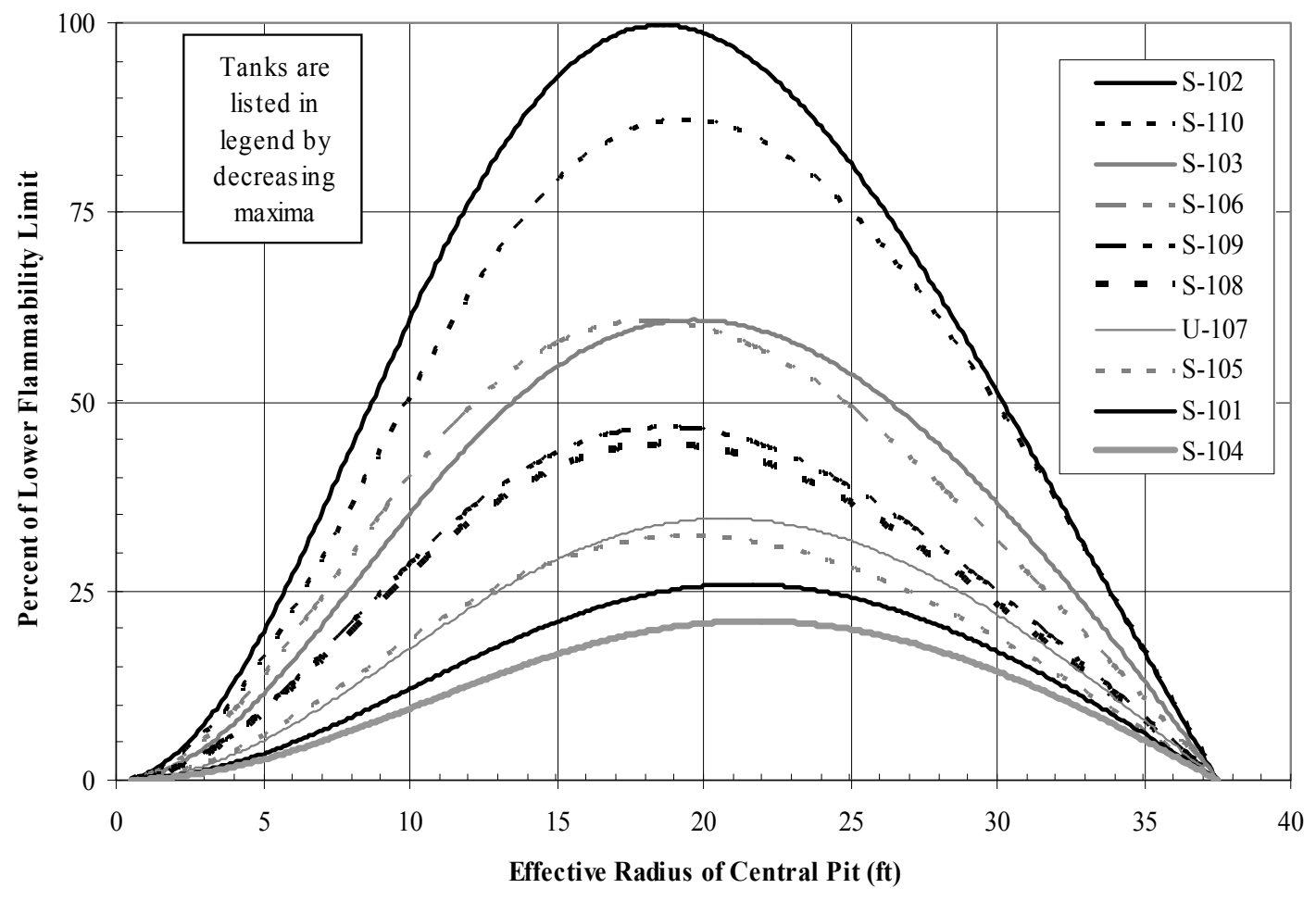

Figure 4.3. Change in Tank Headspace Flammability Due to Drainage of Interstitial Liquid as a Function of Effective Central Pool Radius. The initial central pool liquid height is zero in all cases.

effective central pool radius is less than about $12 \mathrm{ft}$ or more than about $26 \mathrm{ft}$ could not cause a flammable headspace in any of the tanks considered.

One method to ensure the interstitial liquid drainage does not result in the headspace reaching a flammable condition would be to maintain a minimum liquid level in the central pool. This is illustrated in Figure 4.4, where the change in S-102 headspace flammability has been plotted for various values of the initial central pool surface height, $h_{P O O L O}$. As indicated in the figure, maintaining the central pool depth at $52 \mathrm{in}$. would preclude a $75 \%$ of LFL rise (the rise from the operating limit of $25 \%$ of LFL to $100 \%$ of LFL). Similar calculations indicate Tank S-110 would require maintenance of liquid in the central pool at or above $22 \mathrm{in}$. to preclude a $75 \%$ of LFL rise.

An alternative representation of the Tank S-102 drainage-induced gas releases is given in Figure 4.5, where the potential increase in headspace flammability has been plotted as a function of the volume fraction of waste retrieved. Here the curve for $h_{P O O L O}=0$ indicates that during the period between 10 to $50 \mathrm{vol} \%$ of waste retrieved, some limitations should be placed on the minimum liquid level in the pool. 


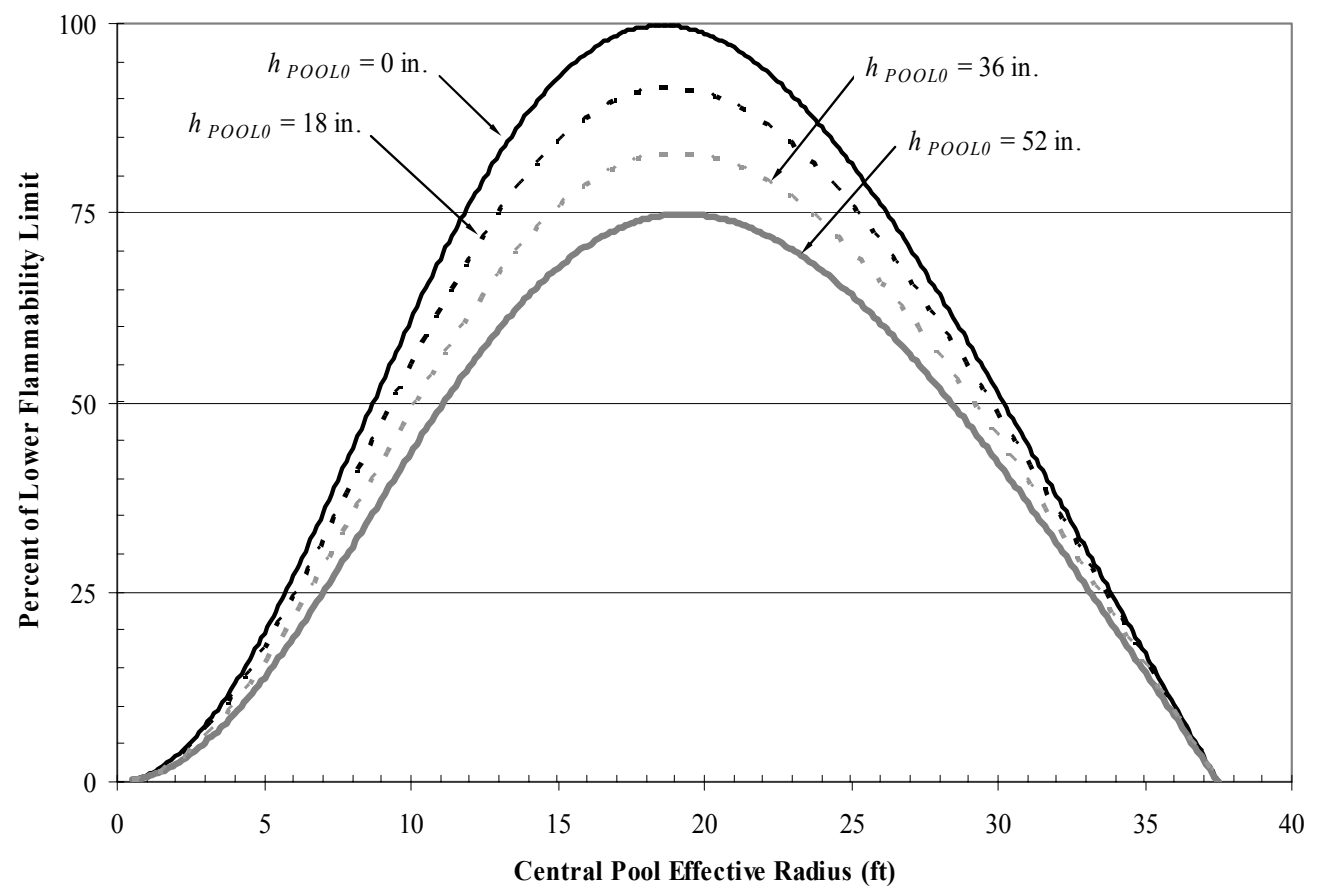

Figure 4.4. Change in Tank S-102 Headspace Flammability Due to Drainage of Interstitial Liquid as a Function of Central Pool Effective Radius for Selected Initial Central Pool Liquid Heights

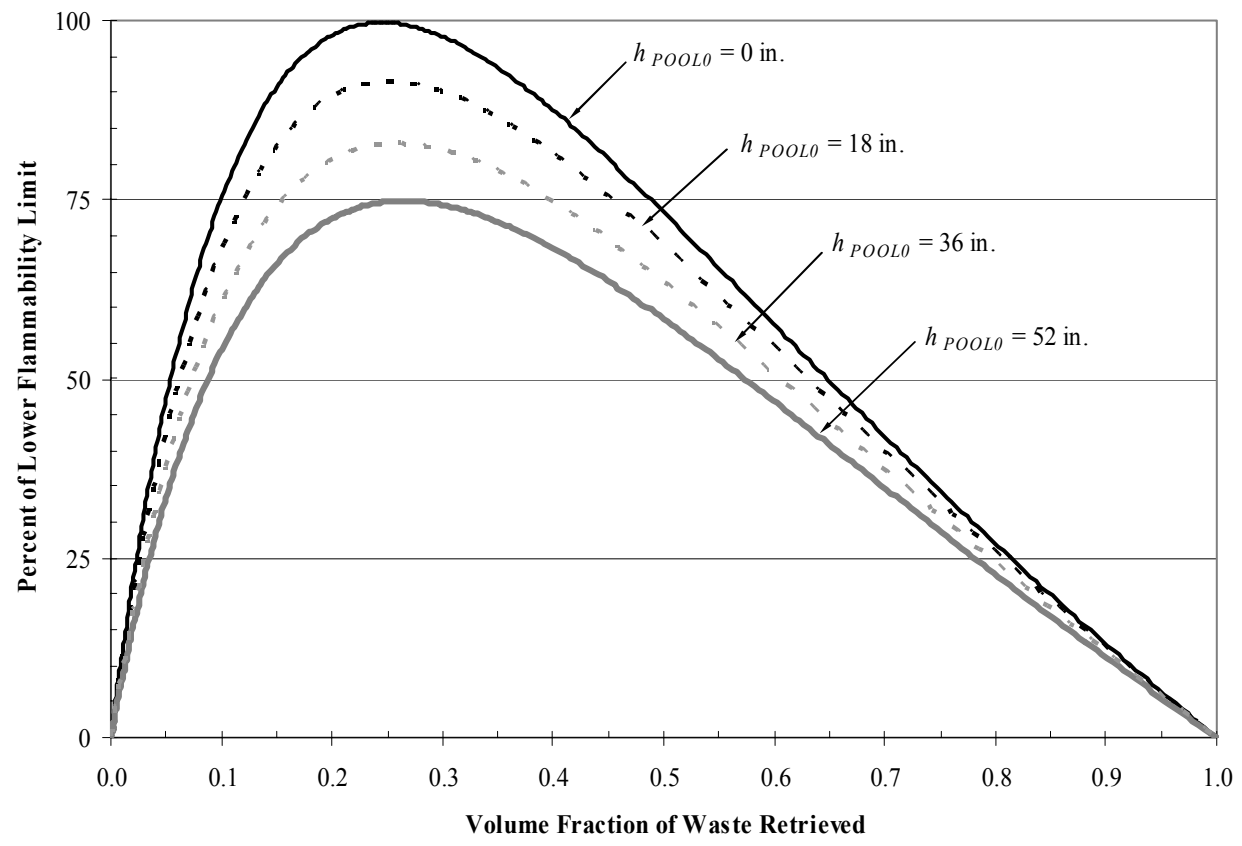

Figure 4.5. Change in Tank S-102 Headspace Flammability Due to Drainage of Interstitial Liquid as a Function of Volume Fraction of Waste Retrieved for Selected Initial Central Pool Liquid Heights 
Results depicted in Figures 4.4 and 4.5 are based on the assumption that the waste above the initial interstitial liquid level in S-102 occupies headspace and is not part of the retrieved waste. When it is assumed that all the waste above the initial interstitial liquid level is retrieved near the start of the retrieval campaign, the curves in Figure 4.5 are lowered (because the headspace volume has been increased) and shifted to the right. This is illustrated in Figure 4.6. Because the extent to which the waste above the initial interstitial liquid level will be retrieved during the early portion of the retrieval campaign cannot be predicted accurately, the guideline to preclude drainage-induced gas releases in Tank S-102 that cause an increase in the headspace flammability of $75 \%$ of the LFL should be revised to require some central pool liquid level control during the period between 10 and $53 \mathrm{vol} \%$ retrieved.

The corresponding calculations for $h_{P O O L 0}=0$ in Tank S-110 suggests that similar restrictions should be placed on the central pool liquid level during the retrieval of that tank during the period of 14 to $50 \mathrm{vol} \%$ waste retrieved.

Eq. (4.12) through (4.14) and the results given in Figures 4.3 and 4.4 were developed for a tank being retrieved by the center-out method. If the center-out method is not applied rigorously, and the waste in the central region is not retrieved to almost the tank floor, the amount of liquid that could drain from undisturbed waste (hence the amount of gas that could be released) will be

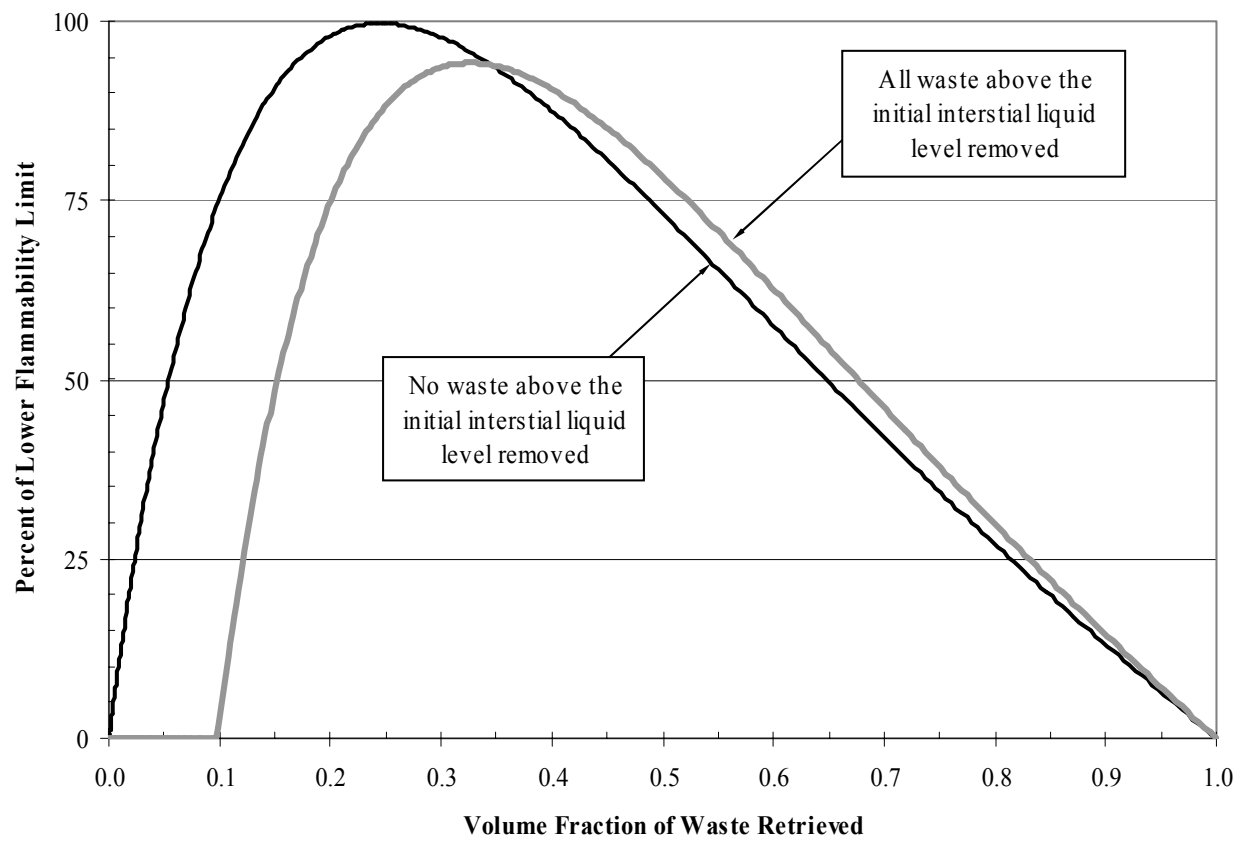

Figure 4.6. Change in Tank S-102 Headspace Flammability Due to Drainage of Interstitial Liquid as a Function of Volume Fraction of Waste Retrieved when Waste above the Initial Interstitial Liquid Level Is Retrieved and Not Retrieved 
reduced accordingly. However, drainage-induced gas releases may also present a hazard if a suitably large void region is created below the surface into which interstitial liquids may drain.

Consider the scenario in which water distributed on the waste surface percolates into the waste instead of dissolving the surface itself, and subsurface dissolution results in significantly increased porosity and/or large voids below the waste surface. If the total volume of voids into which the interstitial liquid can drain, $V_{I L D}$, is large enough, drainage of interstitial liquid from undisturbed (gas-bearing) waste above it could release enough trapped flammable gases to raise the headspace flammability by $75 \%$ of the LFL. One way to prevent this condition during waste retrieval is to require that the lowest liquid level (i.e., in the pump well) in the tank be maintained high enough to preclude drainage of $V_{I L D}$ interstitial liquid. An analysis of this problem is given in Appendix D, and the requirement developed there is

$$
h_{P W L^{*}}=h_{I L}-\left(\frac{0.75 L F L}{\alpha \lambda \pi R^{2}}\right)\left(\frac{P_{H S}}{P_{W}}\right)\left(\frac{T_{W}}{T_{H S}}\right) V_{H S 0}-\left[\left(\frac{0.75 L F L}{\alpha \lambda \pi R^{2}}\right)\left(\frac{P_{H S}}{P_{W}}\right)\left(\frac{T_{W}}{T_{H S}}\right)+1\right] V_{T} \chi
$$

where $h_{P W L^{*}}$ is the minimum height of liquid in the retrieval pump well, and $\chi$ is the volume fraction of waste retrieved. Eq. (4.15) assumes the headspace volume increases as the retrieval progresses according to the relationship

$$
V_{H S}=V_{H S 0}+\chi V_{T} \text {. }
$$

Note that prior to the removal of $\chi V_{T} \geq V_{I L 75 \%}$ there is no minimum requirement on the pump well liquid level, because there would not be enough void present for interstitial liquid drainageinduced gas releases to cause a $75 \%$ of the LFL increase in the headspace. The volume fraction of waste retrieved below which no pump well liquid level restrictions apply is given by

$$
\chi^{*}=\frac{(\phi-\alpha)(0.75 L F L)\left(\frac{P_{H S}}{P_{W}}\right)\left(\frac{T_{W}}{T_{H S}}\right) V_{H S 0}}{\left[\alpha \lambda-(\phi-\alpha)(0.75 L F L)\left(\frac{P_{H S}}{P_{W}}\right)\left(\frac{T_{W}}{T_{H S}}\right)\right] V_{T}}
$$

In other words, no restrictions need be applied to the pump well liquid level until the retrieval campaign has retrieved $\chi^{*}$ of the waste.

Application of Eq. (4.15) and (4.17) to the tanks of interest indicates that no minimum pump well liquid level requirements need be applied to Tanks S-101, S-104, S-105, or U-107. Tanks S-101, S-104, and S-105 do not have enough retained gas to raise the flammability of their headspaces by $75 \%$ of the LFL under any conditions (see Table 2.5 ). Similarly, by the time $\chi^{*}$ is 
reached in Tank U-107 it does not have sufficient retained gas to raise the flammability of its headspace by $75 \%$ of the LFL.

The minimum pump well liquid level given by Eq. (4.15) is plotted in Figure 4.7 for the six tanks that are indicated to need an $h_{P W L}$ control. As indicated by the form of Eq. (4.15), the value of $h_{P W L^{*}}$ decreases linearly with $\chi$. Table 4.3 lists the calculated slope and intercept for $h_{P W L^{*}}$ for

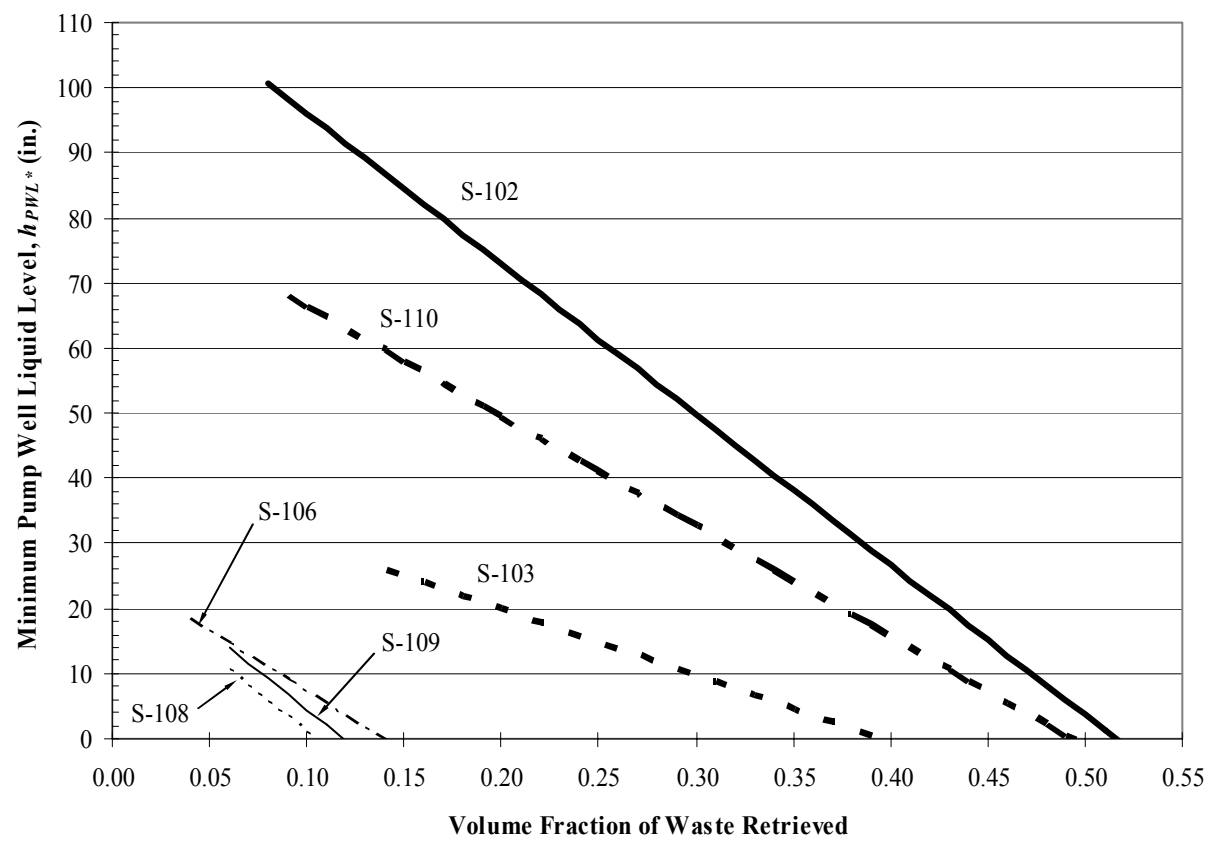

Figure 4.7. Minimum Pump Well Liquid Level, $h_{P W L^{*}}$, as a Function of Volume Fraction of Waste Retrieved

Table 4.3. Parameters for Calculation of $h_{P W L^{*}}$

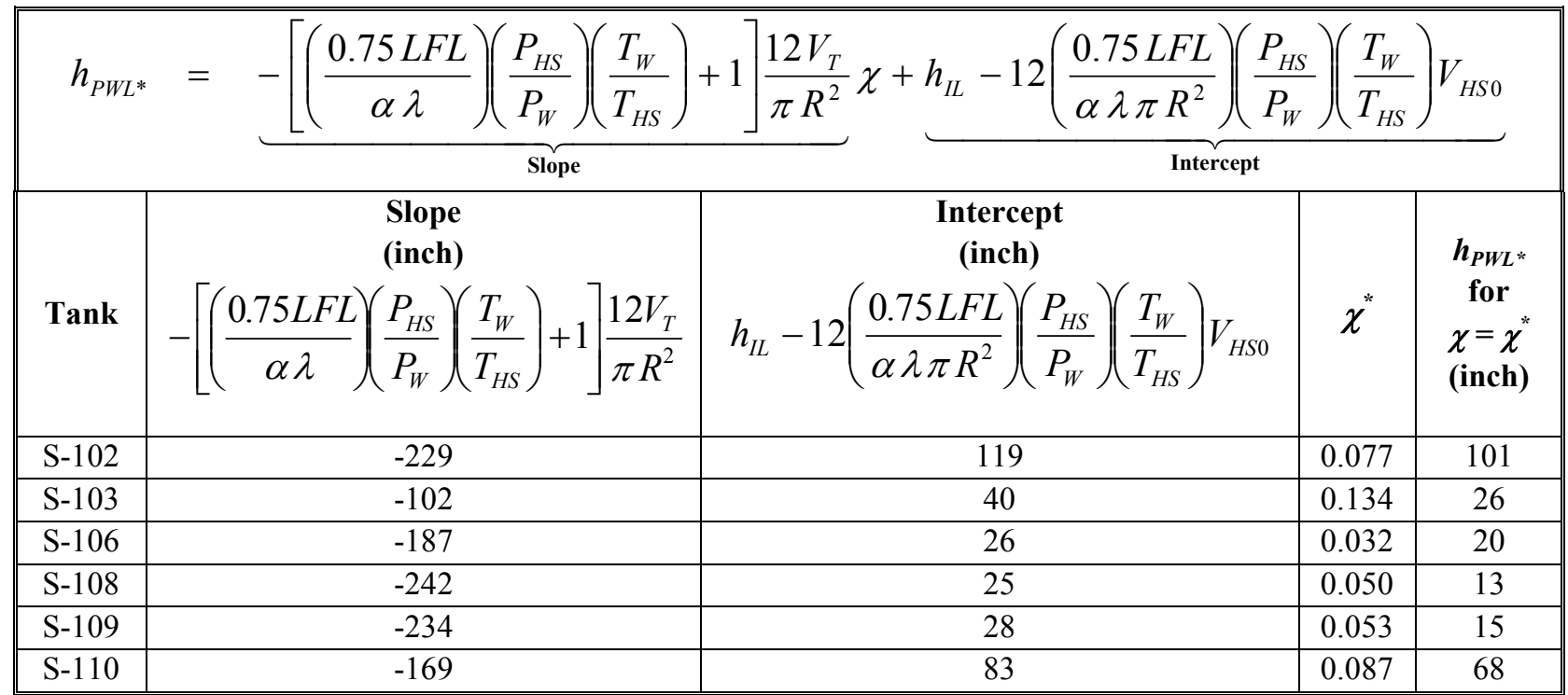


the six tanks that may need $h_{P W L}$ controls. Here $h_{P W L^{*}}$ is given in units of inches, for $R$ in units of feet, and $V_{T}$ and $V_{H S O}$ in units of cubic feet (factor of 12 appearing in the equations in Table 4.3 is the unit conversion factor of feet to inches). The last column in Table 4.3 lists the largest value for $h_{P W L^{*}}$ for each tank, which corresponds to the left-hand end of the lines in Figure 4.7.

\subsubsection{Dissolution after Process Shutdown}

To evaluate whether unsaturated liquids in the tank could dissolve enough waste to raise the headspace to a flammable condition, consider the hypothetical scenario in which a large volume of pure water is placed in the tank and then allowed to dissolve the gas-bearing waste. Assuming negligible ventilation and that dissolution continues until the water is saturated, the change in headspace flammability is given as

$$
\text { Change in headspace flammability }=\frac{\beta_{B W} V_{H 2 O} \alpha}{L F L_{M I X} V_{H S}}\left(\frac{P_{W}}{P_{H S}}\right)\left(\frac{T_{H S}}{T_{W}}\right) \lambda\left(\frac{1}{1+\Gamma}\right) \times 100 \%
$$

where $\beta_{B W}$ is the volume of bulk waste dissolved per volume of water, $V_{H 2 O}$ is the volume of water present, $\alpha$ is the retained gas void fraction, $\lambda$ is the fraction of retained gas that is flammable, and $\Gamma$ is the ratio of waste volume above the interstitial liquid level to waste volume below the interstitial liquid level. The derivation of Eq. (4.18) is given in Appendix B.

Note that the volume of bulk waste dissolved per volume of water, $\beta_{B W}$, is just equal to $V_{B}$ [given by Eq. (4.2)] with $F=0$. Using this relationship, the combination of Eq. (4.2), (4.3), and (4.4) gives

$$
\beta_{B W}=\frac{V_{T}\left(\beta_{L C} \rho_{B R}-1\right)}{\rho_{S} V_{S}} .
$$

The tank headspace volume for this scenario is calculated using the expression

$$
V_{H S}=V_{T A N K}-V_{W<I L L}(1+\Gamma)-V_{H 2 O}
$$

where $V_{T A N K}$ is the total volume of the (empty) tank. Because the headspace volume decreases as water is added in this scenario, even tanks that originally did not have enough retained flammable gas to reach the LFL in their headspaces (see Table 2.5) could present a hazard.

Eq. (4.18), (4.19), and (4.20) were used to calculate the volumes of water necessary to release, by dissolution of saltcake, flammable retained gases sufficient to raise the headspace of each tank by $75 \%$ of the LFL. As above, the dissolution parameters for Tank S-112 given in Table 4.1 were used for all tanks. In the first set of calculations it was assumed that each tank contained all of its original waste, both above and below the interstitial liquid. The inclusion of 
waste above the interstitial liquid level reduces the headspace volume but also reduces the amount of gas released per volume water added. The calculated headspace and required water volumes for this case are listed in the second and third columns, respectively, of Table 4.4.

Table 4.4. Water Volumes Potentially Resulting in a 75\% of LFL Increase in Tank Headspace

\begin{tabular}{|c|c|c|c|c|}
\hline \multirow[b]{2}{*}{ Tank } & \multicolumn{2}{|c|}{$\begin{array}{l}\text { Original Volume of Waste above } \\
\text { Interstitial Liquid Level }\end{array}$} & \multicolumn{2}{|c|}{$\begin{array}{l}\text { All Waste above Interstitial } \\
\text { Liquid Level Removed }\end{array}$} \\
\hline & $\begin{array}{c}\text { Calculated } \\
\text { Headspace Volume } \\
\left(\mathbf{f t}^{3}\right)\end{array}$ & $\begin{array}{c}\text { Volume of Water } \\
\text { (kgal) }\end{array}$ & $\begin{array}{c}\text { Calculated } \\
\text { Headspace Volume } \\
\left(\mathbf{f t}^{3}\right)\end{array}$ & $\begin{array}{c}\text { Volume of Water } \\
\text { (kgal) }\end{array}$ \\
\hline S-101 & 55,233 & 286 & 60,657 & 281 \\
\hline S-102 & 53,097 & 151 & 60,147 & 151 \\
\hline S-103 & 88,615 & 149 & 90,337 & 146 \\
\hline S-104 & 61,498 & 302 & 62,486 & 300 \\
\hline S-105 & 46,735 & 294 & 98,188 & 190 \\
\hline S-106 & 49,977 & 221 & 106,392 & 129 \\
\hline S-108 & 34,251 & 244 & 95,765 & 185 \\
\hline S-109 & 37,264 & 238 & 94,669 & 182 \\
\hline S-110 & 69,008 & 145 & 77,140 & 139 \\
\hline U-107 & 46,679 & 206 & 65,032 & 179 \\
\hline
\end{tabular}

In the second set of calculations it was assumed that all the waste above the interstitial liquid level has been removed by some means, so that $R=0$. This has the effect of increasing the amount of gas released per volume of water added, but also increases the headspace volumes. The calculated headspace and required water volumes for this case are listed in the fourth and fifth columns, respectively, of Table 4.3.

Currently, there are no plans to add large quantities of water to the waste tanks at the start of retrieval operations, ${ }^{(a)}$ nor are there any identified mechanisms by which such large quantities of water could rapidly dissolve saltcake in the current waste configuration. ${ }^{\text {(b) }}$ In the more realistic cases, where the liquid present in the tank is partially saturated or significant amounts of waste have been retrieved prior to the process shutdown, the volumes of liquid necessary to cause a dangerous rise in headspace flammability would be increased correspondingly.

(a) Smaller volumes of water, e.g., less than 10,000 gal, may be added initially to enlarge the central pit around the retrieval pump.

(b) Rapid addition of the water volumes given in Table 4.3 to their respective tanks would result in a liquid layer at the waste surface in each tank. The liquids would be expected to form a stable nonconvective layer with high-density, nearly saturated brine near the submerged solids and low-density, nearly pure water at the liquid surface. Under these conditions, dissolution would proceed only at the relatively slow rate of the diffusion of dissolved salts upward through the liquid. 


\subsection{Discussion}

The results of the gas release analyses for the selected tanks show that under conservative assumptions the flammable gas headspace concentrations can rapidly approach $25 \%$ of the LFL when the tank is passively ventilated. Use of the portable exhauster is not necessary to maintain the headspace hydrogen concentration below this action level, but retrieval rates may be limited by the slow removal of flammable gases by passive ventilation. Use of the portable exhauster anywhere in the assumed operating range of 270 to $475 \mathrm{cfm}$ would prevent the headspace from reaching the action level even if the water jets are very effective at eroding the saltcake (i.e., result in saturated brine with a $30 \mathrm{wt} \%$ solids loading).

Estimated gas release rates given in Table 4.2 and headspace flammability estimates depicted in Figures 4.1 and 4.2 are based on conservative assumptions and very likely exaggerate the potential to reach flammable conditions in the headspace. Specifically, gas void fractions used to estimate retained gas inventories are the $95^{\text {th }}$ percentile values developed by Barker and Hedengren (2003), providing a 95\% confidence that actual void fractions and corresponding flammable gas inventories are smaller than those used in calculations; and gas releases associated with water jets impinging on the waste (i.e., during active waste retrieval) are based on the assumptions that the water is instantaneously saturated and that erosion by the water jets results in a $30 \mathrm{wt} \%$ solids loading of the saturated brine produced. This is consequently a bounding analysis in which most of the input parameters and assumptions are reasonably conservative, and the results are arguably very conservative.

Estimated gas release volumes and conditions leading to headspace flammability after a retrieval process shutdown are also based on conservative assumptions to ensure hazards are not underestimated. Estimated changes in the headspace flammability due to interstitial liquid drainage during a center-out retrieval, depicted in Figures 4.3 and 4.4, are based on no ventilation of the headspace and complete drainage of the waste and release of all the retained gases from the region above the final interstitial liquid level (credit was not even taken for the capillary fringe). Similarly, the guidelines on the minimum pump well liquid level needed to preclude a drainage-induced gas release that would raise the flammability of the headspace by $75 \%$ of the LFL during any non-center-out retrieval shown in Figure 4.7 assume no headspace ventilation and complete drainage and gas release. The potential for unsaturated brine in the tank to release gases was evaluated by assuming the liquid was completely unsaturated (i.e., pure water) and that no headspace ventilation occurred during the time required for the liquids to become $100 \%$ saturated. Given these assumptions, using the values in the third or last columns of Table 4.3 as maximum allowable volumes of free water is very conservative. 


\subsection{References}

Barker SA. 2003. Determination of Hanford Waste Tank Volumes. RPP-13019 Rev. 0, CH2M HILL Hanford Group, Inc., Richland, WA.

Barker SA and DC Hedengren. 2003. Methodology and Calculations for the Assignment of Waste Groups for the Large Underground Waste Storage Tanks at the Hanford Site. RPP-10006 Rev. 2B, CH2M HILL Hanford Group, Inc., Richland, WA.

Cowin JL, WB Barton, JL Huckaby, and CW Stewart. 2003. Process Control Plan for Saltcake Dissolution Retrieval Demonstration in Tank 241-S-112. RPP-15085 Rev. 3A, CH2M HILL Hanford Group, Inc., Richland, WA.

Hanlon BM. 2003. "Waste Tank Summary Report for Month Ending February 28, 2003." HNF-EP-0182 Rev. 179, CH2M HILL Hanford Group, Inc., Richland, WA.

Hedengren DC, TA Hu, MA Kufahl, DJ McCain, CW Stewart, JL Huckaby, LA Mahoney, and KG Rappe. 2001. Data and Observations of Single-Shell Flammable Gas Watch List Tank Behavior. RPP-7249, CH2M Hill Hanford Group, Inc., Richland, WA.

Herting DL and DW Edmonson. 1998. Saltcake Dissolution FY 1998 Status Report. HNF-3427 Rev. 0, Fluor Daniel Hanford, Inc., Richland, WA.

Herting DL. 1999. Saltcake Dissolution FY 1999 Status Report. HNF-5193 Rev. 0, Numatec Hanford Corporation, Richland, WA.

Herting DL. 2000. Saltcake Dissolution FY 2000 Status Report. HNF-7031 Rev. 0, Fluor Hanford, Inc., Richland, WA.

Herting DL. 2001. Saltcake Dissolution FY 2001 Status Report. HNF-8849 Rev. 0, Fluor Hanford, Inc., Richland, WA.

Herting DL. 2002. Saltcake Dissolution FY 2002 Status Report. HNF-12145 Rev. 0, Fluor Hanford, Inc., Richland, WA.

$\mathrm{Hu}$ TA and SA Barker. 2002. Steady-State Flammable Gas Release Rate Calculation and Lower Flammability Level Evaluation for Hanford Tank Waste. RPP-5926 Rev. 2, CH2M HILL Hanford Group, Inc., Richland, WA.

Huckaby JL, JC Evans, KB Olsen, KM Remund, and DS Sklarew. 1997. Measurements of Waste Tank Passive Ventilation Rates Using Tracer Gases. PNNL-11683, Pacific Northwest National Laboratory, Richland, WA. 
Huckaby JL, JC Evans, DS Sklarew, and AV Mitroshkov. 1998. Waste Tank Ventilation Rates Measured with a Tracer Gas Method. PNNL-11925, Pacific Northwest National Laboratory, Richland, WA.

Huckaby JL, LM Peurrung, and PA Gauglitz. 1999. Gas Release During Saltwell Pumping: Interpretation of Operational Data. PNNL-13029, Pacific Northwest National Laboratory, Richland, WA.

Mahoney LA, ZI Antoniak, JM Bates, and ME Dahl. 1999. Retained Gas Sampling Results for the Flammable Gas Program. PNNL-13000, Pacific Northwest National Laboratory, Richland, WA.

Peurrung LM, SM Caley, EY Bian, and PA Gauglitz. 1996. Gas Release During Salt Well Pumping: Model Predictions and Comparisons to Laboratory Experiments. PNNL-11310, Pacific Northwest National Laboratory, Richland, WA.

Stewart CW. 2001. Gas Releases During Saltcake Dissolution for Retrieval of Single-Shell Tank Waste. PNNL-13597, Pacific Northwest National Laboratory, Richland, WA.

Stewart CW, PA Meyer, ME Brewster, KP Recknagle, PA Gauglitz, HC Reid, and LA Mahoney. 1996. Gas Retention and Release Behavior in Hanford Single-Shell Waste Tanks. PNNL-11391, Pacific Northwest National Laboratory, Richland, WA.

Tank Characterization Database. 2003. Pacific Northwest National Laboratory, Richland, WA. Available at: http://twins.pnl.gov/twins3/twins.htm.

Whitney PD. 1995. Screening the Hanford Tanks for Trapped Gas. PNL-10821, Pacific Northwest National Laboratory, Richland, WA.

Zabetakis MG. 1965. Flammability Characteristics of Combustible Gases and Vapors. Bulletin 627, Bureau of Mines, U.S. Department of the Interior, Washington, D.C. 


\section{Appendix A}

Estimation of Bulk Waste Volume Above the Interstitial Liquid Level in Tank 241-S-102 


\section{Appendix A}

\section{Estimation of Bulk Waste Volume Above the Interstitial Liquid Level in Tank 241-S-102}

There is evidence that the current Best Basis Inventory (BBI) may underestimate the volume of waste in Tank S-102 because it does not include a ring of waste above the measured waste surface level. This ring of waste is important here because it affects the calculated tank headspace volume, and consequently affects the estimation of headspace flammability. Two types of evidence for the ring are noted here. First, each of the three waste core samples collected in 1996 and 1998 via the three risers located about 30 feet from the tank center indicated solids above the current waste surface level. Second, saltwell pumping and surface level data from 1999 through 2003 indicate that liquids pumped from the tank were from a central pool, and not from a supernate layer that extended across the entire waste surface. Here the saltwell pumping and surface level are analyzed to determine the bulk volume (solid, liquid, and gas) of this waste ring.

The saltwell pumping rate and waste surface level (as measured by an Enraf ${ }^{\mathrm{TM}}$ ) for retrieval activities in Tank S-102 are shown in Figure A.1. At steady state conditions, it is expected that the Enraf $^{\mathrm{TM}}$ level represents the interstitial liquid level (ILL). The sharp drops in waste level result from waste transfer out of the tank, and the exponential rise after the completion of a transfer is attributable to drainage of interstitial liquid from waste material above the measured surface level. This apparent drainage, together with comparison of the transfer volumes and level history, suggest that waste extends into the headspace above the ILL.

The volume of waste above the ILL that affects the headspace volume may be computed by considering that

$$
V_{W}=V_{L}+V_{R}
$$

where $V_{W}$ is the volume of waste between the initial and final ILL, $V_{L}$ is the volume of original supernatant liquid removed, and $V_{R}$ is the bulk volume of the exposed waste ring. Equation (A.1) is written in terms of the original supernatant removed to exclude the drained volume from 


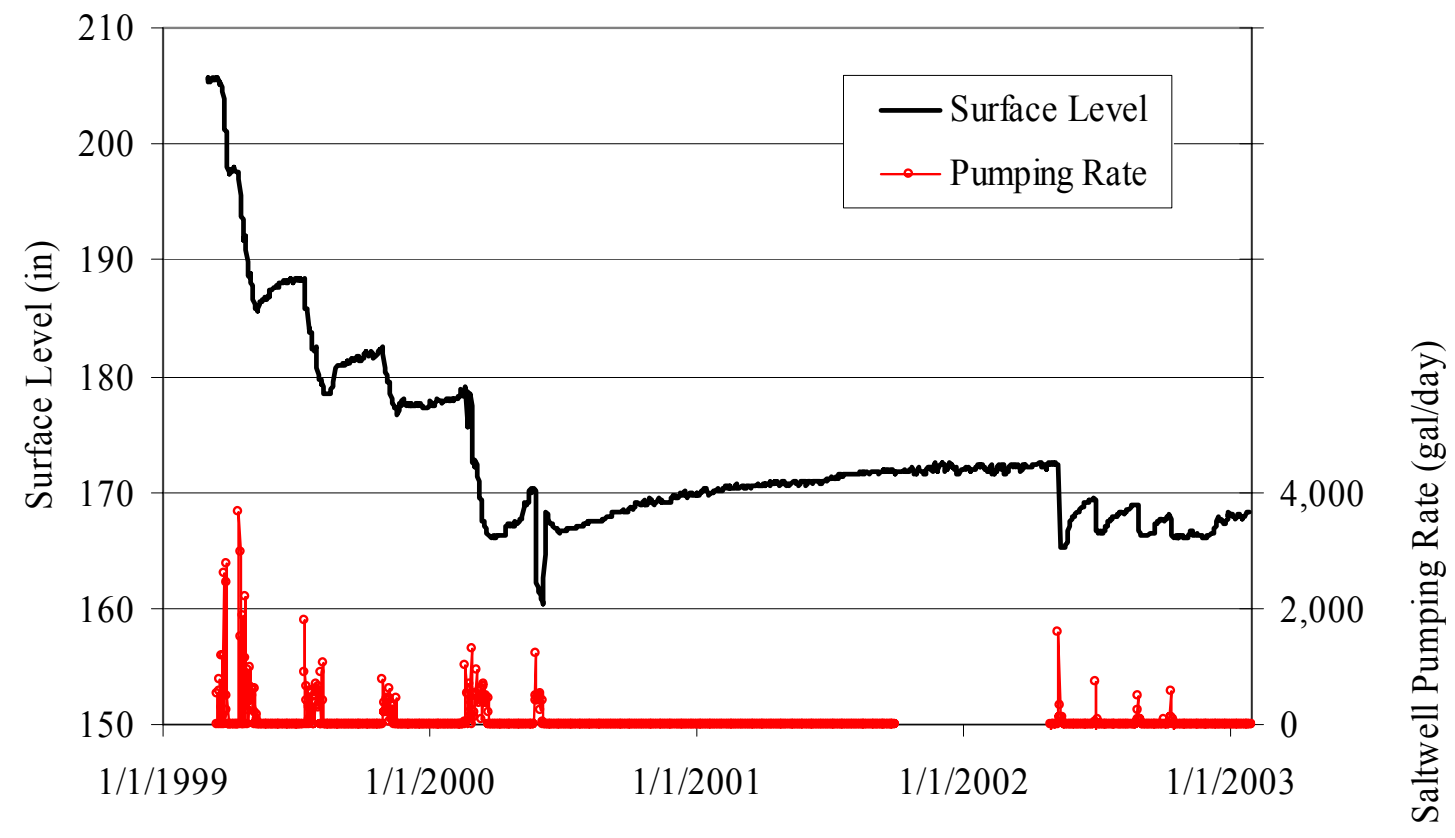

Figure A.1. Surface Level and Saltwell Pumping Rate in S-102

the waste ring in computation of the headspace volume. The volume of waste transferred is comprised of original supernatant liquid and interstitial liquid drained from the waste ring, or

$$
V_{T R}=V_{L}+\gamma V_{R}
$$

where $\gamma$ is the fraction of drainable liquid in the waste ring. The fraction of drainable liquid is assumed to be 0.25 . Solving Eq. (A.1) and (A.2) for $V_{R}$ yields

$$
V_{R}=\frac{V_{W}+V_{T R}}{(1-\gamma)}
$$

The change in the ILL over the time period shown in Figure A.1 is 38.9 in corresponding to $V_{W}=107,130$ gal. With a total transfer volume of 62,139 gal, the volume of the waste ring is approximately 60,000 gal. The effect of the estimated fraction of drainable liquid in the waste ring is shown in Figure A.2. No drainage, which is not supported by the waste level history in Figure A.1, results in a waste ring of approximately 45,000 gal. The volume of the waste ring shows a greater increase as the fraction of drainable liquid approaches the non-solid fraction of the bulk waste. This limit is also not applicable as it does not allow for gas in the pore space. 


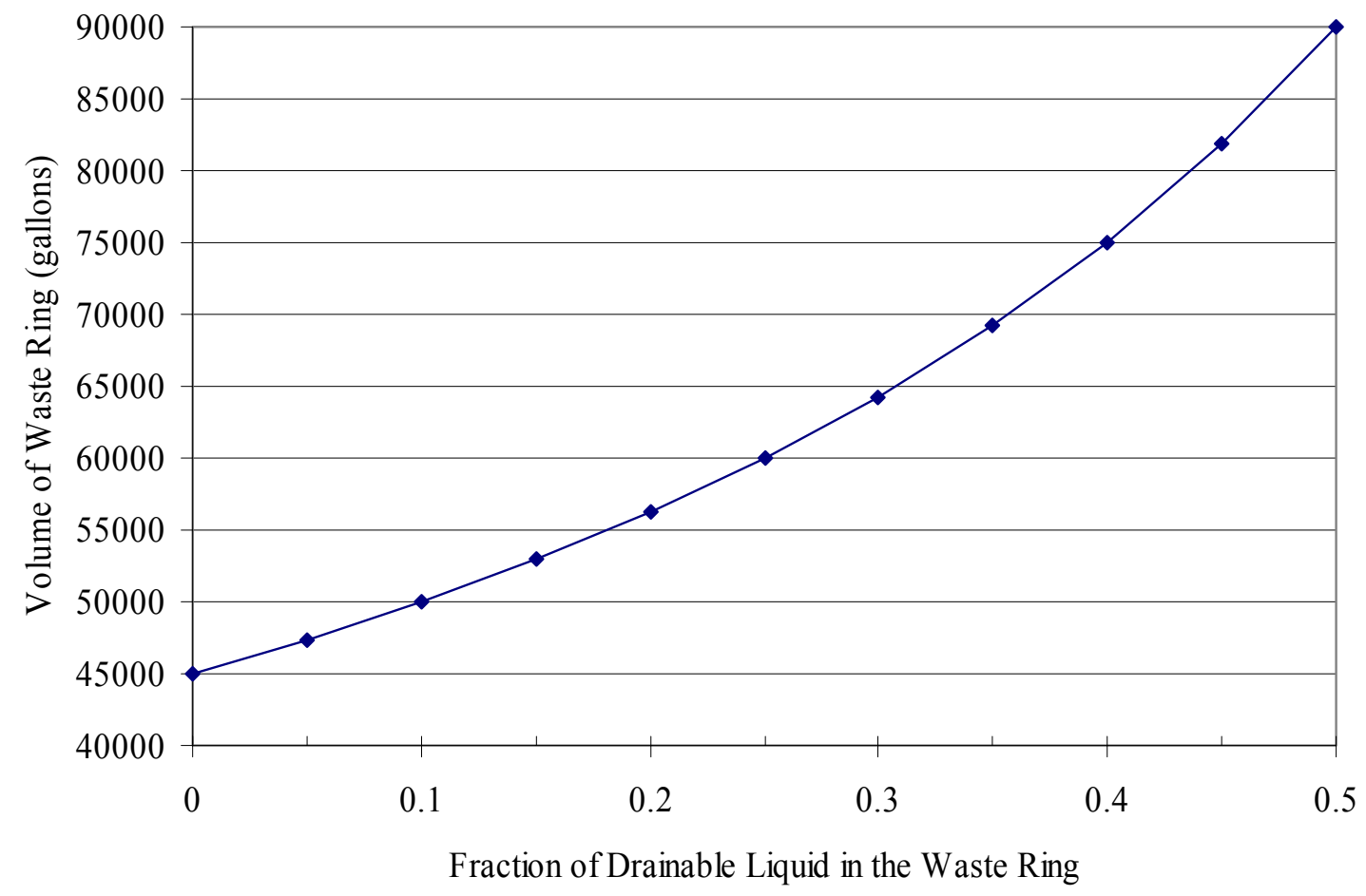

Figure A.2. Waste Ring Volume as a Function of the Drainable Liquid Fraction 


\section{Appendix B}

Gas Release Rate Model Equations 


\section{Appendix B}

\section{Gas Release Rate Model Equations}

Sluicing is capable of mobilizing sediment by creating forces that exceed the strength of the material. The disruption of the sediment releases retained gas into the tank headspace. Gas release during sluicing is therefore a function of the amount of the sediment that is mobilized. The amount of waste material mobilized by a sluicing nozzle or jet is a function of the operational parameters of the jet and the waste characteristics. To bound the problem without modeling the exact physical phenomena, the waste mobilization must be limited by the ability of the product stream (sluicing liquid, solids dissolved into the sluicing liquid, interstitial liquid, and undissolved solids) to "carry" undissolved solids. This appendix presents the computation of the expected gas release as a function of the water added by sluicing based on the undissolved solids loading in the product stream.

Waste parameters that address specific waste dissolution characteristics for Tank S-112 are presented in Cowin et al. (2003). These parameters include:

$\beta_{L C}$ : Volume of brine created by dissolution per volume of water added

$\beta_{B W}$ : Volume of bulk waste dissolved per volume of water added

$\rho_{B R}:$ Density of brine created by dissolution

$\rho_{I L}:$ Density of initial interstitial liquid

$\rho_{S}$ : $\quad$ Density of dry solids (assumed the same for both soluble and insoluble)

$w_{S S}$ : Mass fraction of soluble solids in bulk solids

$V_{T}$ : Total waste volume

Parameters that further characterize the waste are:

$\alpha$ : $\quad$ Volume fraction of gas in the bulk waste (Barker and Hedengren 2003)

$h_{I L}: \quad$ Interstitial liquid level (TWINS) ${ }^{(\mathrm{a})}$

$\phi$ : $\quad$ Porosity of the waste (non-solid volume per total waste volume)

\section{B.1 Gas Release Due to Dissolution and Erosion by Water Jet}

The volume of (void-free) solids in the waste is given by

$$
V_{S}=(1-\phi) V_{T}
$$

The volume of interstitial liquid in the pore space is 


$$
V_{I L}=V_{T}-V_{G}-V_{A}-V_{S}
$$

where $V_{A}$ is the pore-space volume above the interstitial liquid level and $V_{G}$ is the volume of gas retained in the saturated waste below the interstitial liquid level. The gas volume $V_{G}$ is then

$$
V_{G}=\alpha V_{W<I L L}
$$

where $V_{W<I L L}$ is the volume of waste below the interstitial liquid level (computed from $h_{I L}$ ). Assuming that there is no interstitial liquid above $h_{I L}$, the pore-space volume above the interstitial liquid level is

$$
V_{A}=\phi\left(V_{T}-V_{W<I L L}\right)
$$

The mass of solids per bulk waste volume is

$$
M_{S}=\frac{\rho_{S} V_{S}}{V_{T}}
$$

and the mass of interstitial liquid per bulk waste volume is

$$
M_{I L}=\frac{\rho_{I L} V_{I L}}{V_{T}}
$$

The mass of brine created by dissolution per volume of water added is

$$
M_{B R}=\beta_{L C} \rho_{B R}
$$

and the mass of solids dissolved per volume of water added is therefore

$$
M_{D S}=M_{B R}-\rho_{W}
$$

where $\rho_{W}$ is the density of water.

We use a factor $F$ to assign the undissolved solids loading in the product stream or the mass of undissolved solids per total product stream mass. To determine the volume of bulk waste mobilized per volume of water added $\left(V_{B}\right)$ by sluicing to achieve $F$, consider that $F$ is defined as

$$
F=\frac{M_{U}}{M_{U}+M_{B R}+M_{I L} V_{B}}
$$

(a) TWINS: Tank Waste Information System database. http://twins.pnl.gov/twins3/twins.htm. 
where $M_{U}$, the mass of undissolved solids in the product stream per volume of water added, is computed as

$$
M_{U}=V_{B} M_{S}-M_{D S}
$$

Substituting Eq. (B.10) into Eq. (B.9) and solving for the volume of bulk waste mobilized per volume of water added yields

$$
V_{B}=\frac{M_{D S}+F}{M_{S}-F\left(M_{S}+M_{I L}\right)}
$$

To account for disturbance of the nongaseous waste above the interstitial liquid level, it is assumed that the water is applied above and below the interstitial liquid level in proportion to the volumes of these two regions. The average gas volume per volume of waste is then simply the total gas volume, $V_{G}$ (Eq. B.3), divided by the total waste volume, $V_{T}$. The volume of gas released adjusted to headspace temperature, $T_{H S}$, and pressure, $P_{H S}$, per volume of water added is computed from

$$
V_{R G}=\frac{V_{G} V_{B}}{V_{T}}\left(\frac{P_{W}}{P_{H S}}\right)\left(\frac{T_{H S}}{T_{W}}\right)
$$

The average waste temperature is denoted by $T_{W}$, and the average pressure in units of inches of $\mathrm{H}_{2} \mathrm{O}$ at which the retained gas is stored is given by

$$
P_{W}=P_{H S}+\frac{1}{2} S p G h_{I L}
$$

where $S p G$ is the specific gravity of the interstitial liquid. By multiplying Eq. (B.12) by the volumetric flow rate of water into the tank $\left(Q_{\mathrm{H}_{2} \mathrm{O}}\right)$, we can compute the volumetric gas release rate as

$$
Q_{G A S}=V_{R G} Q_{H 2 O}
$$

\section{B.2 Gas Release Due to Interstitial Liquid Drainage During a Process Shutdown}

During a shutdown of the retrieval process, drainage of interstitial liquid from the saltcake into the central pool will release retained gases. Consider the situation in which the central pit around the retrieval pump is approximately a cylinder of radius $r$ and the height of liquid in the 
central pool is $h_{P O O L O}$. Liquid will drain out of the saltcake into the central pool until the new interstitial liquid level and the pool height are equal. The volume of liquid accumulated in the central pool must be equal to the amount of liquid drained from the saltcake:

$$
\pi r^{2}\left(h_{I L^{*}}-h_{P O O L 0}\right)=\pi \theta\left(R^{2}-r^{2}\right)\left(h_{I L}-h_{I L^{*}}\right)
$$

where $h_{I L^{*}}$ is the final height of the interstitial liquid, $R$ is the radius of the tank, and $\theta$ is the volume fraction of interstitial liquid given by

$$
\theta=\phi-\alpha
$$

Substituting (B.16) into (B.15) and rearranging gives

$$
h_{I L^{*}}=\frac{h_{P O O L 0}+h_{I L}(\phi-\alpha)\left(\frac{R^{2}}{r^{2}}-1\right)}{1+(\phi-\alpha)\left(\frac{R^{2}}{r^{2}}-1\right)}
$$

Gas releases associated with this change in interstitial liquid level are calculated by subtracting final retained gas inventory from the initial retained gas inventory. This addresses the reduction in pressure felt by the retained gas and the upward percolation of gas due to bubbles that have expanded as the hydrostatic head was decreased. The initial retained gas inventory (adjusted to the headspace temperature and pressure) is given by the expression

$$
V_{G A S 0}=\alpha V_{W<L L L}\left(1-\frac{r^{2}}{R^{2}}\right)\left(\frac{P_{W}}{P_{H S}}\right)\left(\frac{T_{H S}}{T_{W}}\right)
$$

and the final retained gas inventory is given by

$$
V_{G A S^{*}}=\alpha V_{W<I L L^{*}}\left(1-\frac{r^{2}}{R^{2}}\right)\left(\frac{P_{W^{*}}}{P_{H S}}\right)\left(\frac{T_{H S}}{T_{W^{*}}}\right)
$$

where an asterisk $(*)$ has been used to denote the variable is evaluated at the final condition. In these expressions both $V_{W<I L L}$ and $V_{W<I L L^{*}}$ refer to the total volume of the tank below the interstitial liquid level, initial and final, respectively. To avoid having to include the tank bottom

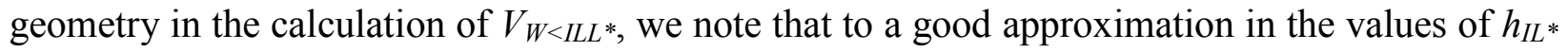
of interest,

$$
V_{W<I L L^{*}}=V_{W<I L L}-\pi R^{2}\left(h_{I L}-h_{I L^{*}}\right)
$$


The decrease in retained gas inventory must equal the gas released into the headspace, which is just the difference between Eq. (B.18) and (B.19):

$$
\Delta V_{G A S}=\alpha\left(1-\frac{r^{2}}{R^{2}}\right)\left(\frac{T_{H S}}{P_{H S}}\right)\left\{V_{W<I L L}\left(\frac{P_{W}}{T_{W}}\right)-\left[V_{W<I L L}-\pi R^{2}\left(h_{I L}-h_{I L^{*}}\right)\left(\frac{P_{W^{*}}}{T_{W^{*}}}\right)\right\}\right.
$$

\section{B.3 Gas Release Due to Continued Dissolution of Saltcake During a Process Shutdown}

The addition of water to a tank will cause retained gas releases to the extent that it dissolves gas-retaining waste. It is assumed here that water introduced or present in the tank when the retrieval process is shut down dissolves the wastes above and below the interstitial liquid level in proportion to the volumes of these waste regions. For example, if one third of the waste is above the interstitial liquid level and two thirds are below it, one third of the water will be used to dissolve the waste above the interstitial liquid level (a region that is assumed to contain no retained gas) and two thirds will be used to dissolve the waste below it. The fraction of water that is used to dissolve gas-retaining waste is

$$
\frac{V_{W<I L L}}{V_{T}}=\frac{1}{1+\Gamma}
$$

where $\Gamma$ is the ratio of waste volumes above and below the interstitial liquid level.

As defined above, $\beta_{B W}$ is the volume of bulk waste dissolved per volume of water, so the volume of retained gas released by dissolution of gas-bearing waste (adjusted for headspace temperature and pressure) is given by

$$
V_{R G}=\alpha \beta_{B W} V_{H 2 O}\left(\frac{1}{1+\Gamma}\right)\left(\frac{P_{W}}{P_{H S}}\right)\left(\frac{T_{H S}}{T_{W}}\right)
$$

where $V_{\mathrm{H} 2 \mathrm{O}}$ is the volume of water available for dissolution. The change in headspace flammability, measured as a change in the percent of the lower flammability limit (LFL) of the mixture, $L F L_{M I X}$, is given by the expression

$$
\frac{\beta_{B W} V_{H 2 O} \alpha}{L F L_{M I X} V_{H S}}\left(\frac{P_{W}}{P_{H S}}\right)\left(\frac{T_{H S}}{T_{W}}\right) \lambda\left(\frac{1}{1+\Gamma}\right) \times 100 \%
$$

where $\lambda$ is the fraction of flammable gases in the retained gas mixture. 


\section{B.4 References}

Barker SA and DC Hedengren. 2003. Methodology and Calculations for the Assignment of Waste Groups for the Large Underground Waste Storage Tanks at the Hanford Site. RPP-10006 Rev. 2B, CH2M HILL Hanford Group, Inc., Richland, WA.

Cowin JL, WB Barton, JL Huckaby, and CW Stewart. 2003. Process Control Plan for Saltcake Dissolution Retrieval Demonstration in Tank 241-S-112. RPP-15085 Rev. 3A, CH2M HILL Hanford Group, Inc., Richland, WA. 


\section{Appendix C}

\section{Headspace Gas Concentration Model}




\section{Appendix C}

\section{Headspace Gas Concentration Model}

Consider a tank containing variable volumes of waste and headspace with inflows and outflows as indicated in Figure C.1. The ventilation inflow, $Q_{\text {VIN }}$, and outflow, Q Vout, carry air into and the headspace atmosphere out of the tank headspace volume, $\mathrm{V}_{\mathrm{HS}}$, respectively. During dissolution, water is added to the waste volume, $\mathrm{V}_{\mathrm{W}}$, at a volumetric flow rate of $\mathrm{Q}_{\mathrm{WIN}}$ and brine is pumped out at the rate Q Q воuт. Gas is released from the waste to the headspace at the volumetric rate $\mathrm{Q}_{\mathrm{GAS}}$, which is understood to be at temperature and pressure of the headspace. The headspace atmosphere and the liquid/gas/solid mixture in the waste volume are both assumed to be incompressible.

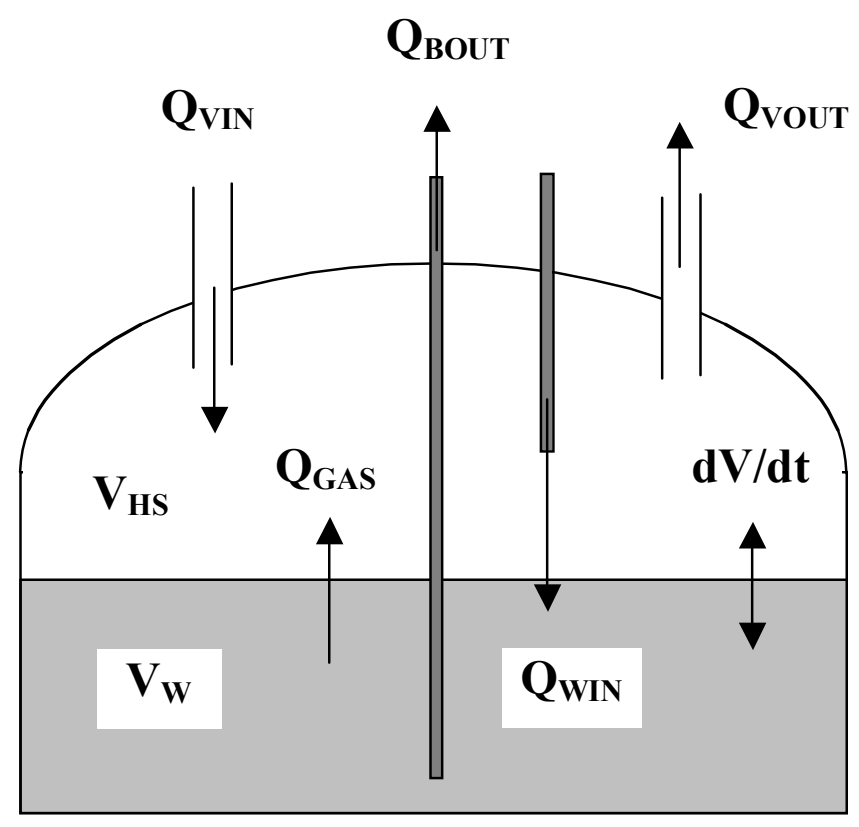

Figure C.1. Schematic of Tank Flow Paths

Let the volume of the tank be fixed but allow the headspace volume and waste volume to vary. The incompressible fluid assumption requires that

$$
\frac{\mathrm{dV}_{\mathrm{HS}}}{\mathrm{dt}}=-\frac{\mathrm{dV}_{\mathrm{W}}}{\mathrm{dt}}
$$

Continuity on the headspace volume can be expressed as 


$$
\frac{\mathrm{dV}_{\mathrm{HS}}}{\mathrm{dt}}=\mathrm{Q}_{\mathrm{VIN}}-\mathrm{Q}_{\mathrm{VOUT}}+\mathrm{Q}_{\mathrm{GAS}}
$$

Assuming the released gas leaves the waste with the pressure at which it was retained, $\mathrm{P}_{\mathrm{GAS}}$, that the volume change during dissolution is negligible, and that gas expansion in the waste due to decrease in hydrostatic pressure is minimal, continuity on the waste volume is written as

$$
\frac{\mathrm{dV}_{\mathrm{W}}}{\mathrm{dt}}=\mathrm{Q}_{\mathrm{WIN}}-\mathrm{Q}_{\text {BOUT }}-\frac{\mathrm{P}_{\mathrm{HS}}}{\mathrm{P}_{\mathrm{W}}} \frac{\mathrm{T}_{\mathrm{W}}}{\mathrm{T}_{\mathrm{HS}}} \mathrm{Q}_{\mathrm{GAS}}
$$

where $\mathrm{P}$ and $\mathrm{T}$ are the average pressure and temperature, respectively, at headspace (subscript HS) and waste (subscript W) conditions.

Substituting Eq. (C.2) and (C.3) into Eq. (C.1) provides an expression for the ventilation outflow, Qout, as a function of the other known inflows and outflows:

$$
\mathrm{Q}_{\text {VOUT }}=\mathrm{Q}_{\mathrm{VIN}}+\mathrm{Q}_{\mathrm{GAS}}\left(1-\frac{\mathrm{P}_{\mathrm{HS}}}{\mathrm{P}_{\mathrm{W}}} \frac{\mathrm{T}_{\mathrm{W}}}{\mathrm{T}_{\mathrm{HS}}}\right)+\mathrm{Q}_{\mathrm{WIN}}-\mathrm{Q}_{\text {BOUT }}
$$

The continuity equation for hydrogen in the headspace, assuming that the hydrogen concentration remains small, can be written as

$$
\frac{\mathrm{d}}{\mathrm{dt}}\left(\mathrm{C}_{\mathrm{H}} \mathrm{V}_{\mathrm{HS}}\right)=\mathrm{Q}_{\mathrm{GAS}} \chi_{\mathrm{H}}-\mathrm{Q}_{\text {VOUT }} \mathrm{C}_{\mathrm{H}}
$$

where $\mathrm{C}_{\mathrm{H}}$ is the headspace hydrogen concentration (vol\%) and $\chi_{\mathrm{H}}$ is the volume fraction of hydrogen in the waste gas. Expanding the derivative and substituting Eqs. (C.3) and (C.4) via Eq. (C.1) yields

$$
\mathrm{V}_{\mathrm{HS}} \frac{\mathrm{dC}_{\mathrm{H}}}{\mathrm{dt}}=\mathrm{Q}_{\mathrm{GAS}} \chi_{\mathrm{H}}-\mathrm{C}_{\mathrm{H}}\left(\mathrm{Q}_{\mathrm{VIN}}+\mathrm{Q}_{\mathrm{GAS}}\right)
$$

Note that, even though it appears outside the time derivative, the headspace volume is a function of time. Assuming that the water inflow, brine-pumping rate, the gas release rate and pressure are constant, Eq. (C.3) and (C.1) can be solved for the headspace volume as a function of time as follows:

$$
\mathrm{V}_{\mathrm{HS}}(\mathrm{t})=\mathrm{V}_{\mathrm{HS} 0}-\left(\mathrm{Q}_{\mathrm{WIN}}-\mathrm{Q}_{\mathrm{BOUT}}-\mathrm{Q}_{\mathrm{GAS}} \frac{\mathrm{P}_{\mathrm{HS}}}{\mathrm{P}_{\mathrm{W}}} \frac{\mathrm{T}_{\mathrm{W}}}{\mathrm{T}_{\mathrm{HS}}}\right) \mathrm{t}
$$


where $\mathrm{V}_{\mathrm{HSO}}$ is the headspace volume at $\mathrm{t}=0$. To simplify further steps, define the following terms:

$$
\begin{aligned}
& \mathrm{Q}_{\mathrm{A}}=\mathrm{Q}_{\mathrm{VIN}}+\mathrm{Q}_{\mathrm{GAS}} \\
& \mathrm{Q}_{\mathrm{B}}=\mathrm{Q}_{\mathrm{WIN}}-\mathrm{Q}_{\text {BOUT }}-\mathrm{Q}_{\mathrm{GAS}} \frac{\mathrm{P}_{\mathrm{HS}}}{\mathrm{P}_{\mathrm{W}}} \frac{\mathrm{T}_{\mathrm{W}}}{\mathrm{T}_{\mathrm{HS}}}
\end{aligned}
$$

Now, substituting these definitions and Eq. (C.7) into Eq. (C.6) and rearranging yields the following ordinary differential equation:

$$
\frac{1}{\mathrm{C}_{\mathrm{H}}-\frac{\mathrm{Q}_{\mathrm{GAS}} \chi_{\mathrm{H}}}{\mathrm{Q}_{\mathrm{A}}}} \frac{\mathrm{dC}_{\mathrm{H}}}{\mathrm{dt}}=-\frac{\mathrm{Q}_{\mathrm{A}}}{\mathrm{V}_{\mathrm{HS} 0}-\mathrm{Q}_{\mathrm{B}} \mathrm{t}}
$$

Eq. (C.9) can be integrated between $t_{1}$ and $t_{2}$ to give

$$
\mathrm{C}_{\mathrm{H}}\left(\mathrm{t}_{2}\right)=\frac{\mathrm{Q}_{\mathrm{GAS}} \chi_{\mathrm{H}}}{\mathrm{Q}_{\mathrm{A}}}+\left(\left(\mathrm{C}_{\mathrm{H}}\left(\mathrm{t}_{1}\right)-\frac{\mathrm{Q}_{\mathrm{GAS}} \chi_{\mathrm{H}}}{\mathrm{Q}_{\mathrm{A}}}\right)\left(\frac{\mathrm{V}_{\mathrm{HS} 0}-\mathrm{Q}_{\mathrm{B}} \mathrm{t}_{2}}{\mathrm{~V}_{\mathrm{HS} 0}-\mathrm{Q}_{\mathrm{B}} \mathrm{t}_{1}}\right)^{\frac{\mathrm{Q}_{\mathrm{A}}}{\mathrm{Q}_{\mathrm{B}}}}\right.
$$

and under the initial conditions that $\mathrm{C}_{\mathrm{H}}=\mathrm{C}_{0}$ at $\mathrm{t}=0$ to yield

$$
\mathrm{C}_{\mathrm{H}}(\mathrm{t})=\frac{\mathrm{Q}_{\mathrm{GAS}} \chi_{\mathrm{H}}}{\mathrm{Q}_{\mathrm{A}}}+\left(\mathrm{C}_{0}-\frac{\mathrm{Q}_{\mathrm{GAS}} \chi_{\mathrm{H}}}{\mathrm{Q}_{\mathrm{A}}}\right)\left(1-\frac{\mathrm{Q}_{\mathrm{B}}}{\mathrm{V}_{\mathrm{HS} 0}} \mathrm{t}\right)^{\frac{\mathrm{Q}_{\mathrm{A}}}{\mathrm{Q}_{\mathrm{B}}}}
$$

The time at which the hydrogen concentration reaches a specified value, $\mathrm{C}_{\mathrm{H}}$, is given by

$$
\mathrm{t}=\frac{\mathrm{V}_{\mathrm{HS} 0}}{\mathrm{Q}_{\mathrm{B}}}\left[1-\left(\frac{\mathrm{C}_{\mathrm{H}}-\frac{\mathrm{Q}_{\mathrm{GAS}} \chi_{\mathrm{H}}}{\mathrm{Q}_{\mathrm{A}}}}{\mathrm{C}_{0}-\frac{\mathrm{Q}_{\mathrm{GAS}} \chi_{\mathrm{H}}}{\mathrm{Q}_{\mathrm{A}}}}\right)^{\frac{\mathrm{Q}_{\mathrm{B}}}{\mathrm{Q}_{\mathrm{A}}}}\right]
$$

If the headspace volume is assumed constant, the solution to Eq. (C.9) for the hydrogen concentration as a function of time under the same initial conditions becomes 


$$
\mathrm{C}_{\mathrm{H}}(\mathrm{t})=\mathrm{C}_{0} \mathrm{e}^{-\frac{\mathrm{Q}_{\mathrm{VIN}}}{\mathrm{V}_{\mathrm{HS}}}}+\frac{\mathrm{Q}_{\mathrm{GAS}} \chi_{\mathrm{H}}}{\mathrm{Q}_{\mathrm{A}}}\left(1-\mathrm{e}^{-\frac{\mathrm{Q}_{\mathrm{VIN}}}{\mathrm{V}_{\mathrm{HS}}} \mathrm{t}}\right)
$$




\section{Appendix D}

Expression for Minimum Interstitial Liquid Level to Prevent Significant Drainage-Induced Gas Releases 


\section{Appendix D}

\section{Expression for Minimum Interstitial Liquid Level to Prevent Significant Drainage-Induced Gas Releases}

An expression for the minimum pump well liquid level to preclude an increase of $75 \%$ of the lower flammability limit (LFL) in the headspace by the draining of interstitial liquid from saturated waste matrix is developed here. The approach taken is to limit either the volume of undisturbed (retained gas-bearing) waste that could be drained and/or the volume of voids into which interstitial liquid can drain.

The expression developed relies on the following assumptions:

The pump well liquid level is at or below the interstitial liquid level (ILL). Therefore, observation of the measured pump well liquid level will limit gas release as defined in the approach developed here.

Waste dissolution occurs predominately in the region above the interstitial liquid ILL. This is based on the interstitial liquid itself being saturated with salts and unable to dissolve more waste. Unsaturated brine above the ILL does not appreciably displace the interstitial liquid below the ILL because it is less dense than the interstitial liquid.

The waste initially has a uniform porosity (in all regions) and retained gas fraction (in un-drained regions). This is consistent with the assumptions made in the main body of this report.

Drainage of interstitial liquid from a region is complete (all the liquid in a region drains to fill voids below it) and all the retained gas in a region that drains is released. These add to the margin of safety in this analysis; much of the liquid cannot drain because of capillary hold-up and much of the retained gas remains trapped because of this liquid.

Drainage of interstitial liquid that releases retained gases occurs only above the pump well liquid level. Interstititial liquid may migrate below this level as hydraulic pressure gradients require, but this does not cause a release of retained gases.

Waste above the initial interstitial liquid level has no drainable liquid or retained gas.

First, note that the volume of retained gas, at the average in situ waste temperature and pressure, required to raised the headspace flammability by $75 \%$ of the LFL is given by

$$
V_{G 75 \%}=\frac{0.75 L F L V_{H S}}{\lambda}\left(\frac{P_{H S}}{P_{W}}\right)\left(\frac{T_{W}}{T_{H S}}\right)
$$


where $\lambda$ is the fraction of the trapped gas that is flammable, and $P$ and $T$ are the average pressure and temperature, respectively, at headspace (subscript HS) and waste (subscript W) conditions. At anytime during the retrieval, the headspace volume, $V_{H S}$, is given by

$$
V_{H S}=V_{H S 0}+\chi V_{T}
$$

where $V_{H S O}$ is the initial headspace volume, and $\chi$ is the volume fraction of bulk waste retrieved at any time. Here the headspace volume is assumed to be increased by the amount of waste retrieved, even though some of the retrieved waste may have been below the waste surface level. This is equivalent to including subsurface voids in the calculation of the headspace volume. The approach is justified because the diffusion of air and flammable gases through the porous waste into and out of the subsurface voids is generally faster than the interstitial drainage rate. Even if a layer of very insoluble waste is encountered, the dissolution of waste beneath it will cause subsidence and a corresponding increase in the headspace volume.

The volume of undisturbed (retained gas-bearing) waste that must be drained to release $V_{G 75 \%}$ is given by

$$
V_{W 75 \%}=\left(\frac{1}{\alpha}\right) V_{G 75 \%}
$$

where $\alpha$ is the volume fraction of retained gas in the bulk waste. Similarly, the volume of interstitial liquid in $V_{W 75 \%}$ is given by

$$
V_{I L 75 \%}=\left(\frac{\phi-\alpha}{\alpha}\right) V_{G 75 \%}
$$

or

$$
V_{I L 75 \%}=(\phi-\alpha) V_{W 75 \%}
$$

where $\phi$ is the porosity of bulk waste. Note that $V_{I L 75 \%}$ is equivalent to the volume of voids that must be present to receive the draining interstitial liquid, $V_{I L D}$. To prevent a drainage-induced

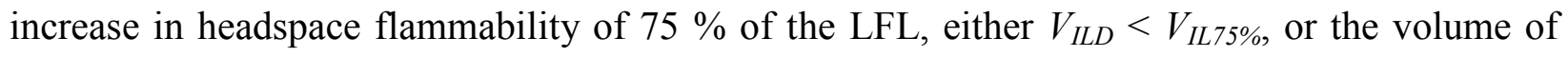
undisturbed (gas-bearing) waste above the pump well liquid level, $V_{D}<V_{W 75 \%}$. The drainable waste volume at any time is given by

$$
V_{D}=\pi R^{2}\left(h_{I L}-h_{P W L}\right)-\varepsilon \chi V_{T}
$$

where $R$ is the tank radius, $h_{I L}$ is the initial interstitial liquid level, $h_{P W L}$ is the pump well liquid level at any point in time, and $\varepsilon$ is the fraction of the waste retrieved from below the initial interstitial liquid level. For example, if $55 \mathrm{vol} \%$ of the waste retrieved was from the region above the initial interstitial liquid level, then $\varepsilon=0.45$. Substituting Eq. (D.6) into the inequality $V_{D}<V_{W 75 \%}$ and solving for the minimum allowable pump well liquid level that will ensure drainage-induced gas releases do not raise the headspace flammability by $75 \%$ of the LFL yields 


$$
h_{P W L}>h_{I L}-\frac{1}{\pi R^{2}}\left[V_{W 75 \%}+\varepsilon \chi V_{T}\right]
$$

The fraction of the waste retrieved below the initial interstitial liquid level, $\varepsilon$, is constrained physically between zero and unity and may not be measured easily. The limiting value of $h_{P W L}$ specified by Eq. (D.7) occurs with $\varepsilon=1$ as indicated by the derivative $\delta h_{P W L} / \delta \varepsilon<0$. This is reasonable, because when $\varepsilon=1$, all of the retrieved waste is from below the initial interstitial liquid level, maximizing the voids between the initial interstitial liquid level and the pump well liquid level. Conversely, with $\varepsilon=0$, all of the retrieved waste is from above the initial interstitial liquid level and no void is available to drain liquid into, thereby placing no limit on the minimum $h_{P W L}$. Therefore, the limiting case of Eq. (D.7) can be written with Eqs. (D.1) and (D.3) as

$$
h_{P W L}>h_{I L}-\frac{1}{\pi R^{2}}\left[\left(\frac{1}{\alpha}\right) \frac{0.75 L F L V_{H S}}{\lambda}\left(\frac{P_{H S}}{P_{W}}\right)\left(\frac{T_{W}}{T_{H S}}\right)+\chi V_{T}\right]
$$

where $V_{H S}$ is given by Eq. (D.2). Note that prior to the removal of $\chi V_{T} \geq V_{I L 75 \%}$ there is no minimum requirement on the pump well liquid level, because there would not be enough void present for interstitial liquid drainage-induced gas releases to cause a $75 \%$ of the LFL increase in the headspace. Combining this with Eq. (D.1) and (D.4) yields the retrieval volume fraction below which no pump well liquid level restrictions apply.

$$
\chi<\frac{(\phi-\alpha)(0.75 L F L)\left(\frac{P_{H S}}{P_{W}}\right)\left(\frac{T_{W}}{T_{H S}}\right) V_{H S 0}}{\left[\alpha \lambda-(\phi-\alpha)(0.75 L F L)\left(\frac{P_{H S}}{P_{W}}\right)\left(\frac{T_{W}}{T_{H S}}\right)\right] V_{T}}
$$


PNNL-14271

Rev. 1

\section{Distribution}

No. of

Copies

$\underline{\text { CH2M HILL Hanford Group }}$

Steve Barker

Blaine Barton

Roger Bauer

Jeni Cowin

Mike Grigsby

Carl Hanson

Larry Kripps

Sarah Landon

Tom May

Dan Reynolds

Ryan Smith
No. of

Copies

Pacific Northwest National Laboratory

S4-44

$\mathrm{S} 7-70$

$\mathrm{S} 7-12$

S7-90

S7-90

$\mathrm{S} 7-70$

S7-90

S7-90

H6-19

S7-90

S7-90
Sheila Bennett

Jim Huckaby (5)

Beric Wells

Lenna Mahoney

Chuck Stewart

Information Release (2)

$\underline{\text { DOE Office of River Protection }}$

Dennis Irby

Jian-Shun Shuen
H6-60

K7-90

K7-15

K7-15

K7-15

K7-15

K1-06

H6-60

Distr. 1 